Portland State University

PDXScholar

$10-2017$

\title{
Racial Bias in Drivers' Yielding Behavior at Crosswalks: Understanding the Effect
}

Kimberly Barsamian Kahn

Portland State University, kimbkahn@pdx.edu

Jean M. McMahon

Portlad State University, mcmah@pdx.edu

Tara Goddard

Portland State University, goddard@pdx.edu

Arlie Adkins

University of Arizona

Follow this and additional works at: https://pdxscholar.library.pdx.edu/trec_reports

Part of the Applied Behavior Analysis Commons, Transportation Commons, and the Urban Studies Commons

Let us know how access to this document benefits you.

\section{Recommended Citation}

Kahn, Kimberly, Jean McMahon, Tara Goddard and Arlie Adkins. 2017. Racial Bias in Drivers' Yielding Behavior at Crosswalks: Understanding the Effect. NITC-RR-869. Portland, OR: Transportation Research and Education Center (TREC). https://doi.org/10.15760/trec.185

This Report is brought to you for free and open access. It has been accepted for inclusion in TREC Final Reports by an authorized administrator of PDXScholar. Please contact us if we can make this document more accessible: pdxscholar@pdx.edu. 


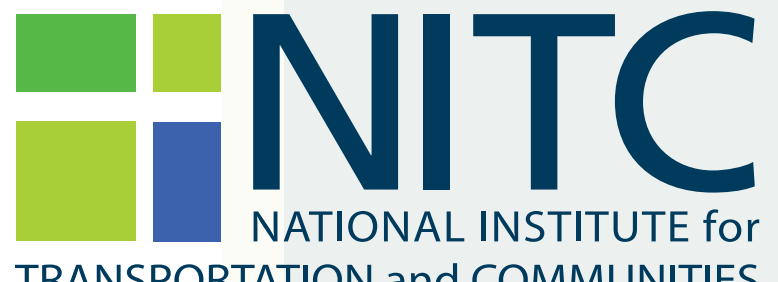

TRANSPORTATION and COMMUNITIES

FINAL REPORT

Racial Bias in Drivers' Yielding Behavior at Crosswalks: Understanding the Effect

NITC-RR-869 $\quad$ October 2017

NITC is a U.S. Department of Transportation

national university transportation center.

HI! TREC 



\section{RACIAL BIAS IN DRIVERS' YIELDING BEHAVIOR AT CROSSWALKS: UNDERSTANDING THE EFFECT}

Final Report

NITC-RR-869

by

PI: Kimberly Barsamian Kahn

Portland State University

Collaborators:

Jean McMahon, Portland State University

Tara Goddard, Portland State University

Arlie Adkins, University of Arizona

for

National Institute for Transportation and Communities (NITC)

P.O. Box 751

Portland, OR 97207
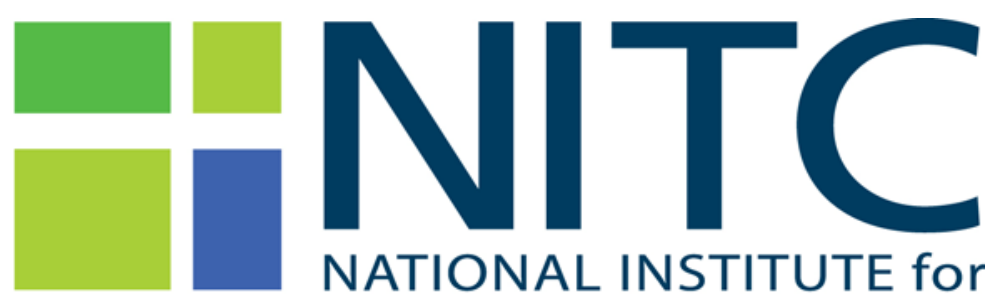

TRANSPORTATION and COMMUNITIES

October 2017 



\section{ACKNOWLEDGEMENTS}

This project was funded by the National Institute for Transportation and Communities (NITC). The authors would like to thank Jaboa Lake, J. Katherine Lee, Maria Villarreal, and members of the Portland State University GRASP Lab for their assistance with this project. A special thank you to all who served as pedestrians for these studies, and to Oregon Walks and Unite Oregon for their help with the focus groups.

\section{DISCLAIMER}

The contents of this report reflect the views of the authors, who are solely responsible for the facts and the accuracy of the material and information presented herein. This document is disseminated under the sponsorship of the U.S. Department of Transportation University Transportation Centers Program in the interest of information exchange. The U.S. Government assumes no liability for the contents or use thereof. The contents do not necessarily reflect the official views of the U.S. Government. This report does not constitute a standard, specification, or regulation.

\section{RECOMMENDED CITATION}

Kahn, Kimberly, Jean McMahon, Tara Goddard and Arlie Adkins. 2017. Racial Bias in Drivers' Yielding Behavior at Crosswalks: Understanding the Effect. NITC-RR-869. Portland, OR: Transportation Research and Education Center (TREC). 


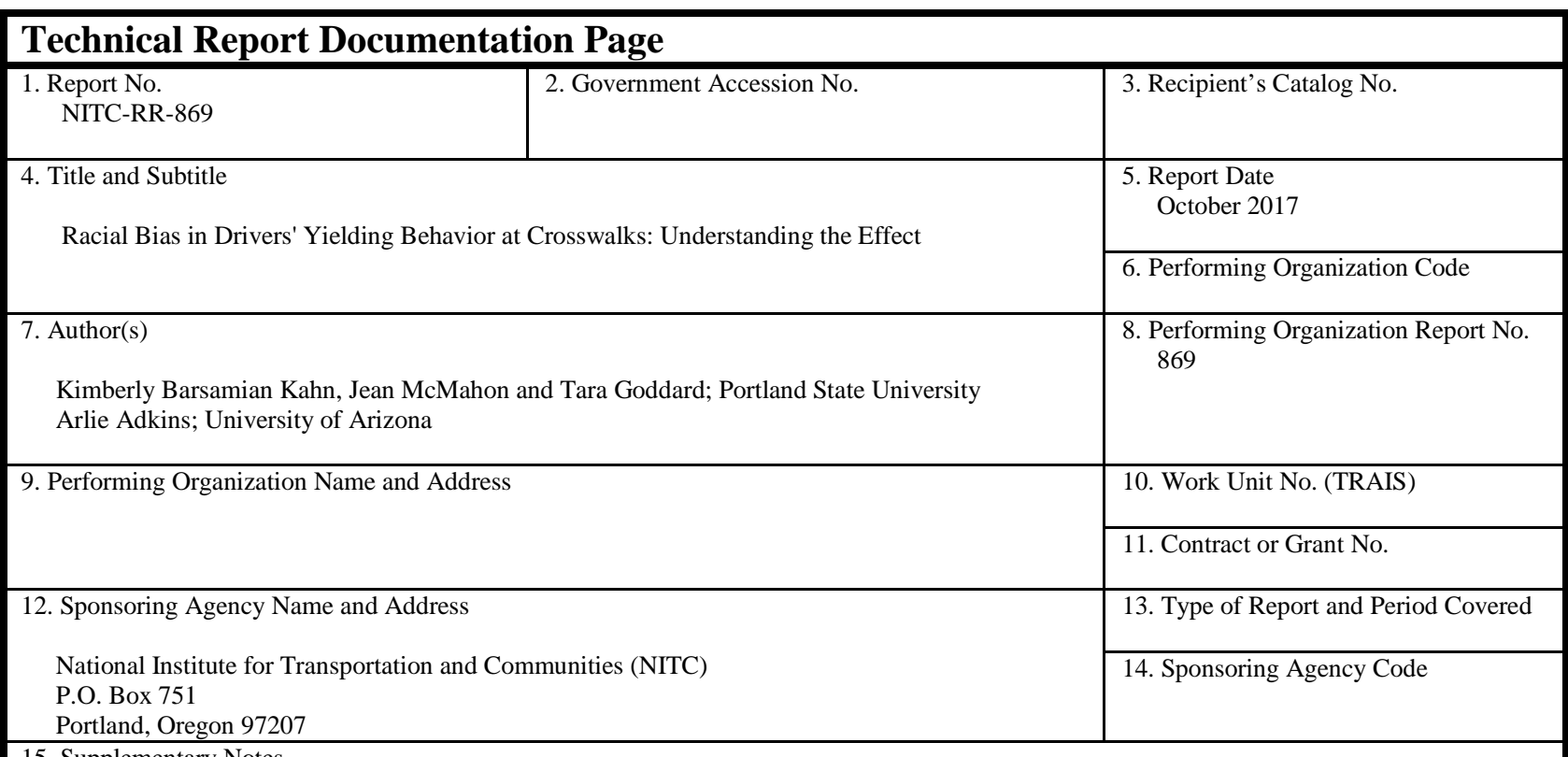

15. Supplementary Notes

\section{Abstract}

This project explores social identity factors (race and gender) that influence drivers' behavior in interactions with pedestrians at crosswalks. One dangerous potential point of conflict for pedestrians within the transportation system is interactions with drivers at crosswalks (NHTSA, 2009). In 2010, there was one crash-related pedestrian death every two hours and an injury every eight minutes, and racial minorities are disproportionately represented in these pedestrian fatalities (CDC, 2013). In light of this disparity, this project examines whether racial discrimination occurs at crosswalks, which may lead to disparate crossing experiences and disproportionate safety outcomes. Racial minorities experience racial discrimination across various domains in society. Consistent with this societal pattern, it is hypothesized that drivers will exhibit racial bias when making decisions about whether or not to stop for pedestrians waiting to cross the street at a crosswalk, which may reflect conscious or nonconscious biases. Our initial research on this topic revealed the predicted racial bias in drivers' yielding behavior at crosswalks: Black male pedestrians were passed by twice as many cars as, and waited 32\% longer than, White male pedestrians (Goddard, Kahn and Adkins, 2015). This study expands on these prior findings to examine the effect of additional pedestrian, driver, and crosswalk characteristics on drivers' yielding behavior with pedestrians.

17. Key Words

Social equity, safety
18. Distribution Statement

No restrictions. Copies available from NITC: www.nitc-utc.net
19. Security Classification (of this report)

Unclassified
20. Security Classification (of this page)

Unclassified
22. Price 


\section{TABLE OF CONTENTS}

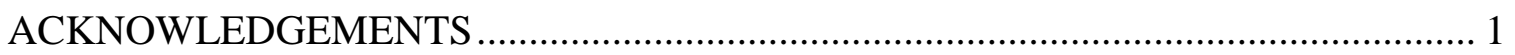

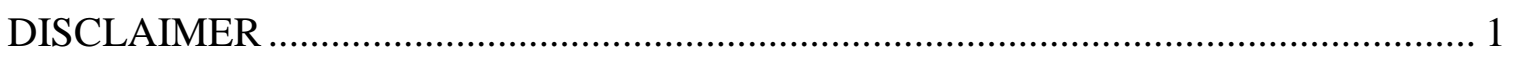

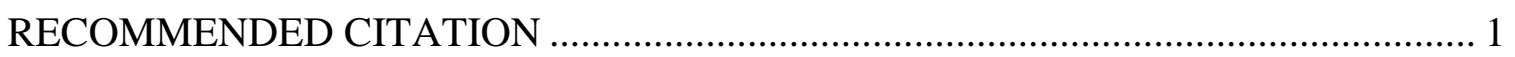

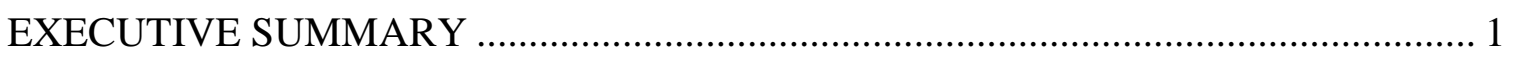

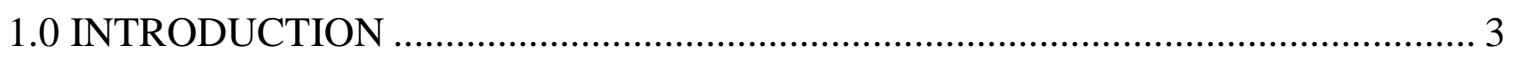

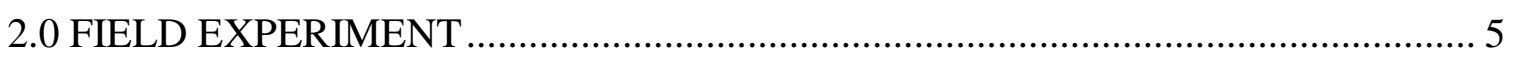

2.1 PURPOSE

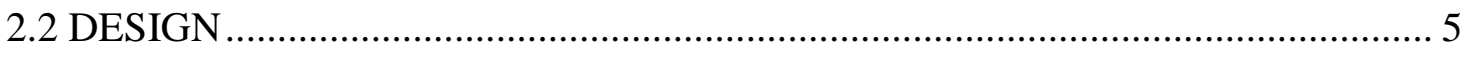

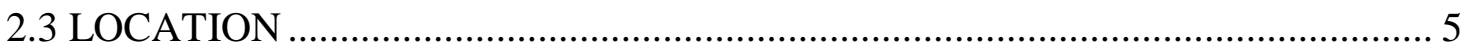

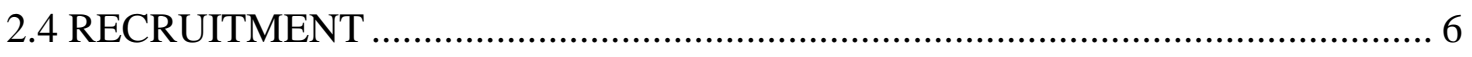

2.5 PROCEDURE

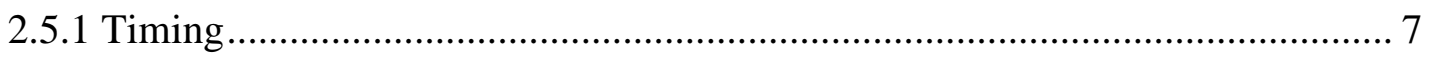

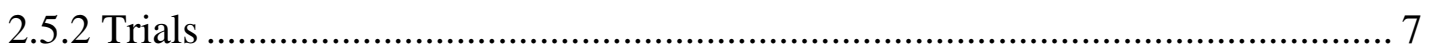

2.5.3 Recorded Data............................................................................................ 7

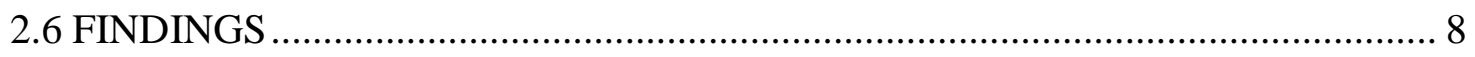

2.6.1 Phase 1 Results: Unmarked crosswalk ........................................................... 8

2.6.1.1 First car stop..................................................................................... 9

2.6.1.2 Number of cars passing without yielding ................................................. 10

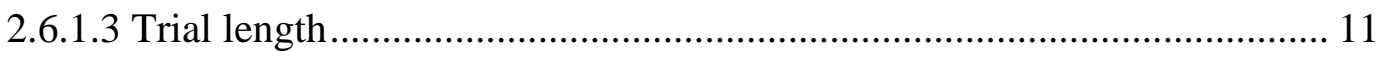

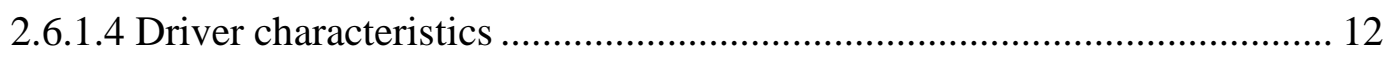

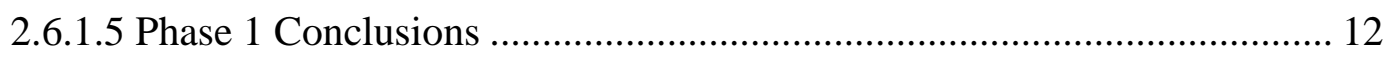

2.6.2 Phase 2 Results: Marked Crosswalk ............................................................ 12

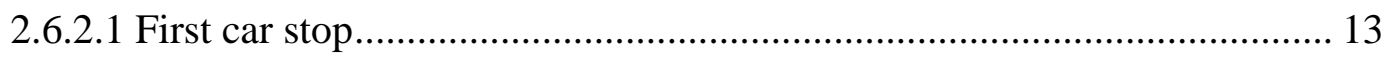

2.6.2.2 Number of cars passing without yielding ................................................ 14

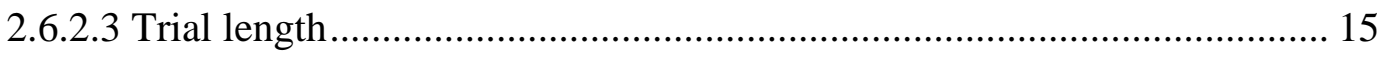

2.6.2.4 Driver characteristics .......................................................................... 16

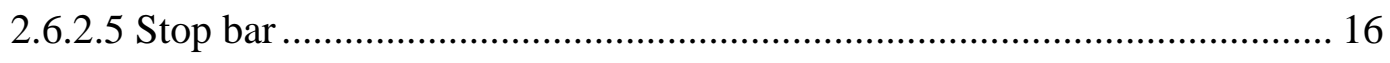

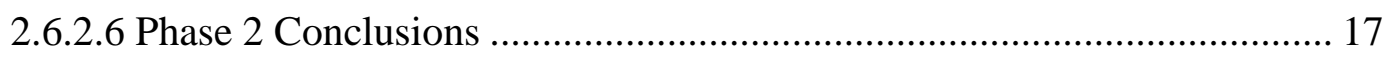

2.7 FIELD EXPERIMENT CONCLUSIONS ………….......................................... 19

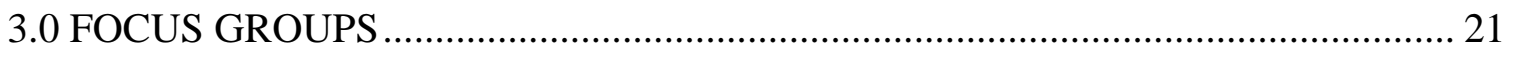

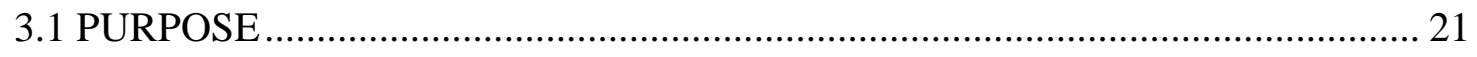

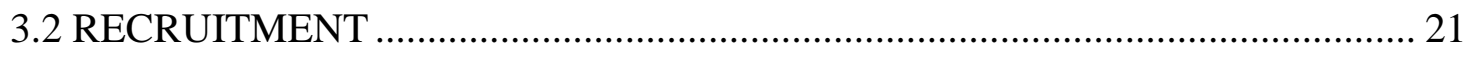




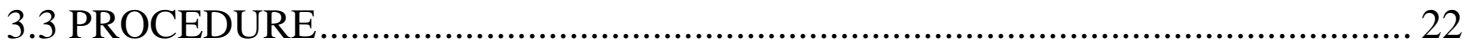

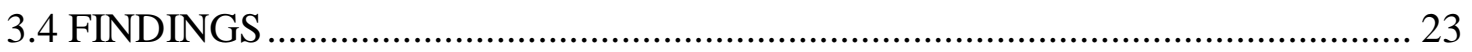

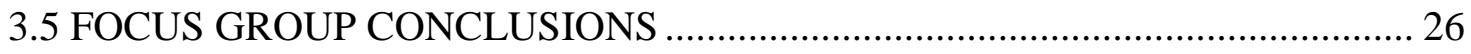

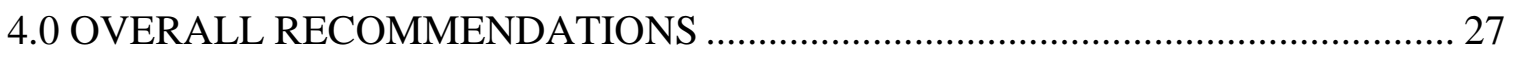

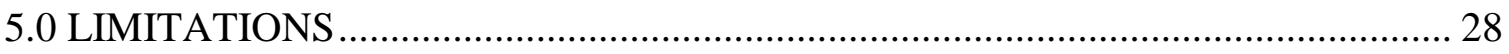

6.0 FUTURE DIRECTIONS FOR RESEARCH.................................................. 29

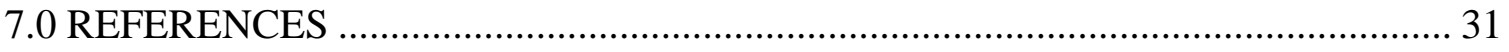

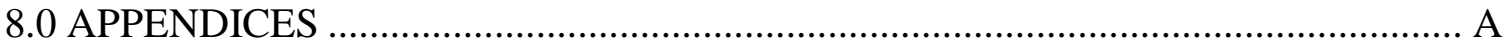

APPENDIX A: Primary trial coding form.............................................................. A

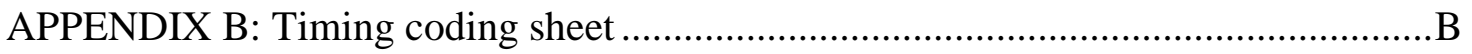

APPENDIX C: First Stop, Number Passed, Stop Bar coding sheet ..............................

APPENDIX D: Driver characteristics coding sheet ............................................. D

APPENDIX E: Screening Form for Focus Group .................................................. E

APPENDIX F: Interview Guide for Focus Groups ............................................. F 


\section{LIST OF TABLES}

Table 2.1: Means, standard deviations, and frequencies for results from Phase 1

(unmarked crosswalk) and Phase 2 (marked crosswalk). .9

\section{LIST OF FIGURES/PHOTOS}

Figure 2.1: Marked crosswalk location used during Phase 2.........................................6

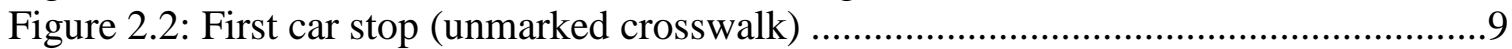

Figure 2.3: Cars passing without yiedling (unmarked crosswalk).................................10

Figure 2.4: Trial length (unmarked crosswalk)...................................................... 10

Figure 2.5: First car stop (marked crosswalk) ..........................................................13

Figure 2.6: Cars passing without yiedling (marked crosswalk)....................................14

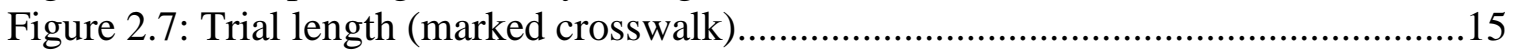

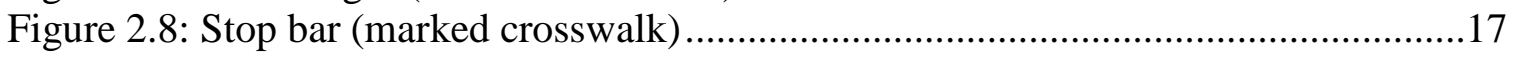

Figure 2.9: Oregonian Crossing campaign image......................................................20 


\section{EXECUTIVE SUMMARY}

This project explores social identity factors (race and gender) that influence drivers' behavior in interactions with pedestrians at crosswalks. One dangerous potential point of conflict for pedestrians within the transportation system is interactions with drivers at crosswalks (NHTSA, 2009). In 2010, there was one crash-related pedestrian death every two hours and an injury every eight minutes, and racial minorities are disproportionately represented in these pedestrian fatalities (CDC, 2013). In light of this disparity, this project examines whether racial discrimination occurs at crosswalks, which may lead to disparate crossing experiences and disproportionate safety outcomes.

Racial minorities experience racial discrimination across various domains in society. Consistent with this societal pattern, it is hypothesized that drivers will exhibit racial bias when making decisions about whether or not to stop for pedestrians waiting to cross the street at a crosswalk, which may reflect conscious or nonconscious biases. Our initial research on this topic revealed the predicted racial bias in drivers' yielding behavior at crosswalks: Black male pedestrians were passed by twice as many cars as, and waited 32\% longer than, White male pedestrians (Goddard, Kahn and Adkins, 2015).

This study expands on these prior findings to examine the effect of additional pedestrian, driver, and crosswalk characteristics on drivers' yielding behavior with pedestrians. Specifically, this study investigates the roles of 1) pedestrian race, 2) pedestrian gender, 3) crosswalk design (unmarked intersection crosswalk vs. marked crosswalk), and 4) drivers' identity characteristics (male vs. female, White vs. minority) on drivers' yielding behavior with pedestrians. A controlled field experiment in which Black and White male and female pedestrians crossed the street at two different types of crosswalks (unmarked vs. marked) was conducted, while trained coders marked drivers' yielding behavior. Results indicated that overall stopping rates were very low at the unmarked crosswalk, and few differences emerged based on pedestrian race and gender. When the crosswalk became marked, stopping rates greatly increased; however, treatment was less equitable. Drivers were less likely to stop for Black and male pedestrians, and when they did stop, they were more likely to stop closer to Black male and Black female pedestrians. These effects occurred regardless of drivers' race and gender.

In order to better understand African American and Black people's experiences as pedestrians, three focus groups were conducted. The results supported the findings of the field experiment. Overall, African American and Black focus group participants perceived that drivers treated them differently based on their race by not stopping or infringing on their space in crosswalks. These negative experiences lead to increased stress and harms their walking trips.

Elucidating the roles of pedestrians' race and gender, drivers' race and gender, and crosswalk design on drivers' stopping behavior with pedestrians is an important step toward developing policies that promote safe transportation experiences. Although marking the crosswalk increased drivers' stopping behavior for pedestrians, it also increased the likelihood of discrimination based on pedestrians' race and gender. To reduce this disparity in treatment, it is recommended that marked crosswalks include 
additional markings and/or design to reduce the sense that yielding is discretionary and to increase driver yielding compliance. Stricter enforcement of driver's yielding at crosswalks can also help to make drivers stop equally for pedestrians. Increasing overall stopping rates will help promote more equitable stopping for all pedestrians. 


\subsection{INTRODUCTION}

Pedestrians are most vulnerable when they are crossing the street, as pedestrian deaths often occur during street crossings (NHTS, 2003). Racial minorities are overrepresented in pedestrian fatalities, with the fatality rates for Black and Hispanic men (3.93 and 3.73 per 100,000 population) being twice the rate for White men (1.78), even when controlling for alcohol use, higher traffic exposure in urban areas, and socioeconomic status (CDC, 2013). One potential reason for this disparity may be in the different treatment that racial minority pedestrians experience when trying to cross the street. That is, drivers' yielding behaviors may be influenced by a pedestrian's race, resulting in different experiences for racial minority pedestrians that may ultimately affect their safety.

Prior research has demonstrated that drivers do not treat all pedestrians the same. Drivers' yielding behavior is influenced by the demographic characteristics of both the pedestrian and the driver. For instance, drivers of high-status cars are less likely to yield to pedestrians than those with low-status cars (Piff, Stancato, Côté, Mendoza-Denton and Keltner, 2012), and are more likely to yield to people who are in their own age group (Rosenbloom, Nemrodov and Ben Eliyahu, 2006) or disabled (Harrell, 1992.) While yielding to pedestrians may be the law or the prevailing norm, these findings suggest that drivers may perceive yielding as a courtesy or at their own discretion, and do so differentially depending on the type of pedestrian they encounter.

In our initial investigation into this topic (Goddard, Kahn and Adkins, 2015), we tested whether pedestrian race influenced drivers' stopping behavior with Black and White male pedestrians. In a controlled field experiment in which Black and White male pedestrians waited to cross the street at a marked crosswalk in Portland, Oregon, Black male pedestrians were passed by twice as many cars and experienced wait times that were $32 \%$ longer than those found for White male pedestrians. This behavior may reflect drivers' implicit racial attitudes, which are subtle, biased beliefs that individuals hold beneath their conscious awareness. Pro-white, anti-Black implicit attitudes are held by a large percentage of Americans and are a cause of discriminatory behaviors (Nosek et al., 2007). Driving and stopping involve fast-paced decisions with numerous distractions, and may be perceived as discretionary, which are conditions under which implicit attitudes are often predictors of behavior (Fazio and Olson, 2003; Greenwald, Poehlman, Uhlmann and Banaji, 2009). If Black pedestrians experience longer wait times at crosswalks, this could encourage risky crossing behaviors, which could potentially contribute to the disparate pedestrian fatality rates. A later study using a similar crossing paradigm with Black and White women in Las Vegas found that drivers in high-income areas were less likely to yield to the Black female pedestrian when she was in the roadway, again highlighting the potential safety issues faced by Black pedestrians trying to crossing the street (Coughenour et al., 2017).

Based on these findings, we extended this research by examining how pedestrian race and gender interact to influence drivers' yielding behavior. In addition to race, this study also examined female pedestrians, as the inclusion of gender is crucial to understanding the full range of racial discrimination and is often neglected in studies of prejudice (Goff and Kahn, 2013). We also examined whether the presence of a marked crosswalk (with zebra stripes, MUTCD-approved regulatory and advisory signs, and a 
stop bar) influenced drivers' stopping behavior, and whether it does so differentially depending on the identity characteristics of the pedestrian. Given that both curb extensions (Johnson, 2005) and signs warning drivers to yield to pedestrians (Van Houten and Malenfant, 1992) increase compliance, it is possible that their presence reduces bias in stopping decisions. Alternatively, while signage may help in promoting more stopping, their nonobligatory nature may leave enough discretion for drivers' biases to affect their decisions to stop. Finally, we test whether driver characteristics (gender and race) also influence stopping decisions. Social psychological theories of prejudice suggest that White males direct more prejudice and discrimination at racial minority males (Sidanius and Pratto, 2001), which would imply that White male drivers may be the least likely to stop for Black male pedestrians. Alternatively, we might find that these biased stopping decisions occur across driver race and gender identities, suggesting an implicit bias and a more pervasive problem.

Finally, to better understand the perspective of racial minority pedestrians, focus groups were conducted to probe African Americans' experiences as pedestrians at crosswalks in Portland, Oregon. Focus groups allow racial minorities to describe their personal experiences crossing the street and how they feel they are treated by drivers. The focus groups can help reveal whether any objective discrepancies in yielding behavior are perceived by racial minority pedestrians, and whether that had any effect on their walking experience or their travel behavior.

To test these hypotheses, two studies were conducted: 1) A controlled field experiment in which pedestrians' race and gender, drivers' race and gender, and crosswalk design (marked vs. unmarked) were compared to examine drivers' bias in yielding behavior, and 2) a series of three focus groups with members of the African American and Black community in Portland to probe their experiences as pedestrians and any discrimination they report at crosswalks. We report the results from both studies below. 


\subsection{FIELD EXPERIMENT}

\subsection{PURPOSE}

The purpose of this study was to experimentally examine the role of pedestrian race, pedestrian gender, and crosswalk design on drivers' yielding behavior toward pedestrians attempting to cross the street. The field experiment systematically varied pedestrian race and gender, and the presence or absence of a marked crosswalk, to see what effect these variables had on drivers' yielding behavior. Driver demographics (drivers' race and gender) were also examined to study their influence on stopping behavior.

\subsection{DESIGN}

We conducted a field experiment with a between-subjects factorial design, with pedestrian race (Black vs. White) and gender (male vs. female) as the independent variables, and drivers' behaviors as the dependent variables. The experiment was run twice at the same location: first, at an unmarked crosswalk (Phase 1), and then approximately nine months later at the same location following the installation of a crosswalk consisting of "zebra” stripes, crosswalk signage, and a car stop bar (Phase 2). Trained coders recorded the outcome of each crossing, allowing for examination of different treatment by pedestrian race and gender.

\subsection{LOCATION}

The crosswalk that was selected for both phases of the experiment was located at Southeast $14^{\text {th }}$ Avenue and Belmont Street in Portland, Oregon. This is a two-lane, oneway street with consistent vehicle and pedestrian traffic, near single-family homes and small businesses. It is a thriving and well maintained business district and neighborhood near downtown Portland, Oregon. This crosswalk was two blocks downstream from an intersection with traffic lights and had a new fleet of cars passing approximately once every three to four minutes.

During Phase 1 of the experiment, the crosswalk at this intersection was unmarked. In Oregon, all intersections, even if they are unmarked, are legal crosswalks that require drivers to yield. On April 9, 2016, the City of Portland marked the crosswalk at this location. The changes included the installation of "zebra" stripes on the pavement, signage directing drivers to stop for pedestrians ahead, and a stop bar marked on the pavement approximately 10 feet before the intersection, indicating where cars should stop (seen in Figure 2.1 below). Phase 2 of data collection occurred more than two months after the installation of the new crosswalk, in order to allow drivers to grow familiar with the design change. 


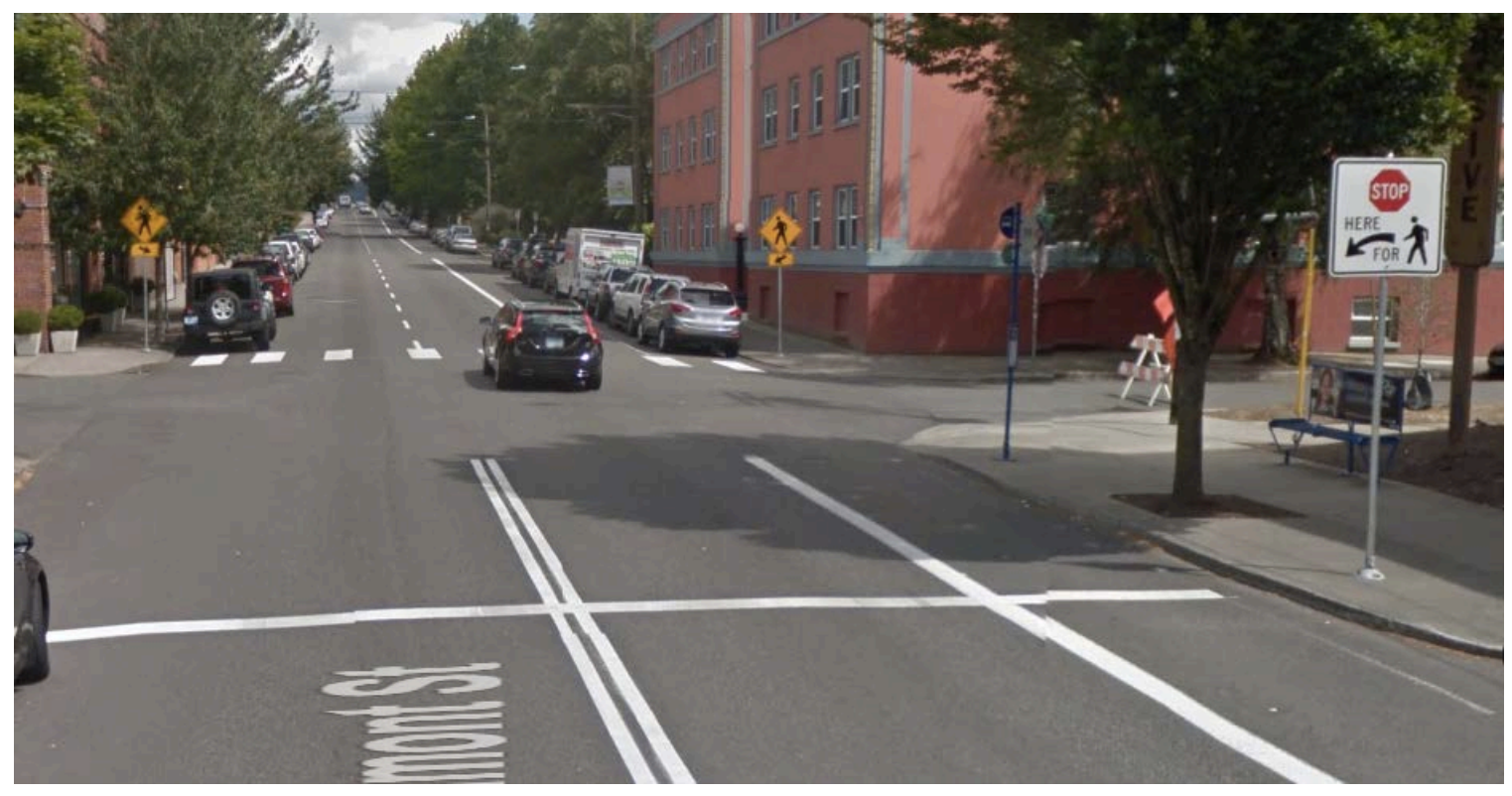

Figure 2.1: Marked crosswalk location used during Phase 2

(Source: Google street view)

\subsection{RECRUITMENT}

For each phase of the experiment, 12 people (three Black men, three White men, three Black women, and three White women) were recruited to serve as pedestrians in the study (for a total of 24 pedestrians). These were residents of Portland who served as the pedestrians crossing the street during the field experiment while the research team recorded how drivers treated them at crosswalks.

Study pedestrians were recruited on the Portland State University campus, on Craigslist, and through various local alumni networks. They were all young adults between 18 and 30 years old and received $\$ 10$ an hour for their participation (for as many hours completed up to 25 hours total). The average age of the pedestrians in Phase 1 was 24.6 years (Black men: ages 25, 23, and 26; Black women: ages 19, 23, and 25; White women: ages 25, 28, and 19; White men: ages 28, 30, and 24) and for Phase 2 was 23.0 years (Black men: ages 25, 25, and 18; Black woman: age 28; White women: ages 24, 22, and 19; White men: ages 27, 23, and 19). Despite small variations in actual ages, all pedestrians were perceived to be of similar ages across each race and gender group and drivers would view them as similarly aged when quickly encountering them at crosswalks. All study pedestrians were "prototypical” in appearance, meaning they were easily identified as their correct race and gender, and had an average build. They had no visible tattoos or facial piercings. During data collection, the appearance of each study pedestrian was standardized by having pedestrians wear identical plain gray T-shirts that were provided for them and blue denim pants, with their hair down and no visible jewelry. The standardized neutral appearance of the pedestrians attempts to control for confounding factors, so that any differences in treatment can be explained by pedestrian race and gender. Pedestrians were trained in the crossing procedure so that they all 
followed the same steps during the field trials (see below in procedure for details on crossing procedure).

\subsection{PROCEDURE}

\subsubsection{Timing}

Phase 1 took place over the span of two weeks in September 2015. Phase 2 took place over two weeks in June 2016. All trials took place during afternoon sessions between 2 p.m. and 5 p.m. to avoid traffic congestion that would restrict free-flow conditions.

\subsubsection{Trials}

Each trial consisted of one pedestrian attempting to cross the road at the designated crossing spot. A member of the research team would signal the beginning of each crossing trial, which occurred when the first car after a traffic light change crossed a marked starting point approximately 200 feet upstream of the study crosswalk. Once signaled, the study pedestrian (one of the 12 pedestrians who were part of the study for each phase) would approach the edge of the crosswalk. The pedestrian would stand at the edge of the curb (not in the street), position their body toward oncoming traffic, and look at the oncoming cars to indicate their intent to cross the street. The trial ended and timing ceased whenever one of the following happened:

1) A car clearly yielded and stopped, allowing the pedestrian to safely cross.

2) The entire platoon of cars passed the pedestrian without stopping (and the next platoon was stopped at the upstream stoplight).

Once the trial ended, the pedestrian crossed the street and passed out of sight before returning to the crosswalk for their next trial. The next pedestrian was cued once the prior pedestrian had crossed the street and was no longer visible. Pedestrians were given a randomized order to cross the street, such that pedestrian race and gender were randomized across trials (e.g., first a White male would cross, then a White female, then a Black male, etc.). Pedestrians waited for their turn to cross in a vacant lot two blocks away from the crosswalk, not visible to the drivers on Southeast Belmont Street.

Trials in which nonstudy pedestrians or bicyclists joined the study pedestrian at the crosswalk were continued but then excluded from final analyses, leaving only trials in which the designated study pedestrians were alone at the unmarked crosswalk. Trials were conducted over the span of two weeks during off-peak hours in the afternoon to avoid overly congested traffic. Data collection was suspended on days with inclement weather and resumed when conditions returned to mild and clear.

\subsubsection{Recorded Data}

Five members of the research team coded the drivers' behaviors at each trial. Members of the research team (positioned inconspicuously at a nearby restaurant and bus stop with 
clear sightlines to the intersection) recorded the following variables using coding sheets (See Appendices A-D):

1) First car stop: whether the first car to reach the crosswalk stopped for the pedestrian, recorded as yes or no.

2) Cars passed: if a car did stop, the number of cars that passed the pedestrian before a car stopped, recorded as a count of cars.

3) Trial length: the amount of time for the pedestrian to cross (in seconds). Timing began when the pedestrian was signaled to approach the crosswalk curb and ended when a car clearly yielded or stopped, or the entire fleet of cars had passed.

4) Driver stop characteristics: if a car did stop for the pedestrian, the race (coded as: white, nonwhite, unknown) and gender (coded as: male, female, unknown) of the driver who stopped to let the pedestrian pass.

5) Stop bar (Phase 2 only): whether the car that yielded to the pedestrian stopped with its front bumper over or behind the designated stop bar at the marked crosswalk (coded as before or after). A car that stopped before the stop bar is obeying the signage and leaving the pedestrian a wide berth to cross, whereas a car that stopped after the stop bar was stopping closer to the pedestrian and infringing on the crossing space. Because the stop bar was positioned further back from the intersection, it is possible that a car could stop after the stop bar, but still allow enough space for the pedestrian to cross. It is therefore a measure of how close or far the car stopped, but not necessarily that a car was inside or outside the marked crosswalk.

\subsection{FINDINGS}

\subsubsection{Phase 1 Results: Unmarked crosswalk}

A total of 330 trials was conducted at the unmarked crosswalk during Phase 1. Eleven trials in which the study pedestrian was joined by a nonstudy pedestrian or cyclist were eliminated. A total of 319 trials remained (90 White female, 67 Black female, 91 White male, 71 Black male). The number of trials completed by each individual pedestrian ranged from 17-35. For each of the following tests, the conventional cutoff of $p<.05$ was used as an indicator of statistical significance.

In 60 out of 319 trials (18.8\%), one car from the passing platoon stopped for the pedestrian; thus, in the vast majority of trials, no driver yielded to the pedestrian who was waiting to cross. The low overall stopping rate may limit the effect of pedestrians' race and gender on drivers' behavior by establishing a floor effect. See Table 2.1 for a summary of the results from Phase 1. 
Table 2.1: Means, standard deviations, and frequencies for results from Phase 1 (unmarked crosswalk) and Phase 2 (marked crosswalk).

\begin{tabular}{|c|c|c|c|c|c|}
\hline & $\begin{array}{l}\text { White } \\
\text { Men }\end{array}$ & $\begin{array}{l}\text { White } \\
\text { Women }\end{array}$ & $\begin{array}{l}\text { Black } \\
\text { Men }\end{array}$ & $\begin{array}{c}\text { Black } \\
\text { Women }\end{array}$ & $\begin{array}{c}\text { Omnibus } \\
\text { test }\end{array}$ \\
\hline Phase 1 & & & & & \\
\hline First car & $6 / 91$ & $0 / 90$ & $1 / 71$ & $2 / 67$ & $\chi^{2}(3, \mathrm{~N}=319)=7.86, p=.05$ \\
\hline $\begin{array}{r}\text { Number of } \\
\text { cars }\end{array}$ & $\begin{array}{c}M=7.11 \\
S D=7.77\end{array}$ & $\begin{array}{c}M=7.07 \\
\mathrm{SD}=4.29\end{array}$ & $\begin{array}{c}\mathrm{M}=8.40 \\
\mathrm{SD}=7.40\end{array}$ & $\begin{array}{c}M=5.82 \\
\mathrm{SD}=6.16\end{array}$ & $F(1,55)=.51, p=.48$ \\
\hline $\begin{array}{r}\text { Trial } \\
\text { length }\end{array}$ & $\begin{array}{c}M=26.38 \\
S D=10.03\end{array}$ & $\begin{array}{l}\mathrm{M}=28.79 \\
\mathrm{SD}=8.02\end{array}$ & $\begin{array}{c}M=28.01 \\
S D=10.14\end{array}$ & $\begin{array}{c}\mathrm{M}=28.12 \\
\mathrm{SD}=9.04\end{array}$ & $F(1,314)=1.19, p=.28$ \\
\hline $\begin{array}{l}\text { Phase } 2 \\
\quad \text { First car }\end{array}$ & $59 / 105$ & $76 / 122$ & $50 / 108$ & $23 / 45$ & $\chi^{2}(3, \mathrm{~N}=380)=6.25, p=.10$ \\
\hline $\begin{array}{r}\text { Number of } \\
\text { cars }\end{array}$ & $\begin{array}{l}M=1.50 \\
S D=2.24\end{array}$ & $\begin{array}{l}M=1.73 \\
S D=3.11\end{array}$ & $\begin{array}{l}M=2.05 \\
S D=3.01\end{array}$ & $\begin{array}{l}\mathrm{M}=1.19 \\
\mathrm{SD}=1.43\end{array}$ & $F(1,373)=2.99, p=.09$ \\
\hline $\begin{array}{r}\text { Trial } \\
\text { length }\end{array}$ & $\begin{array}{l}\mathrm{M}=7.78 \\
\mathrm{SD}=6.39\end{array}$ & $\begin{array}{l}\mathrm{M}=8.79 \\
\mathrm{SD}=8.44\end{array}$ & $\begin{array}{c}M=8.55 \\
\mathrm{SD}=7.49\end{array}$ & $\begin{array}{c}M=8.32 \\
\mathrm{SD}=6.56\end{array}$ & $F(1,394)=.56, p=.46$ \\
\hline Stop bar & $55 / 105$ & $67 / 122$ & $31 / 108$ & $15 / 46$ & $\chi^{2}(3, N=381)=21.56, p<.001$ \\
\hline
\end{tabular}

\subsubsection{First car stop}

Out of the 319 trials, the first car in the platoon to reach the unmarked crosswalk stopped for the pedestrian in only 9 trials (2.8\%), an extremely low first-car stopping rate. The overall chi-square test determined that there was a difference in the frequency with which the first car stopped for a pedestrian group, $\chi 2(3, N=319)=7.86, p=.05$, see Figure 2.2; however, none of the simple effects was significantly different from any other. Despite being non-significant, the pattern [White women ( $0 \%$ of trials), Black women (3\% of trials), White men (7\% of trials), and Black men, (1\% of trials)] suggests that White men may be favored in having the first car stop, although the overall low first stop rates should be taken into consideration. 


\section{First car stop (unmarked crosswalk)}

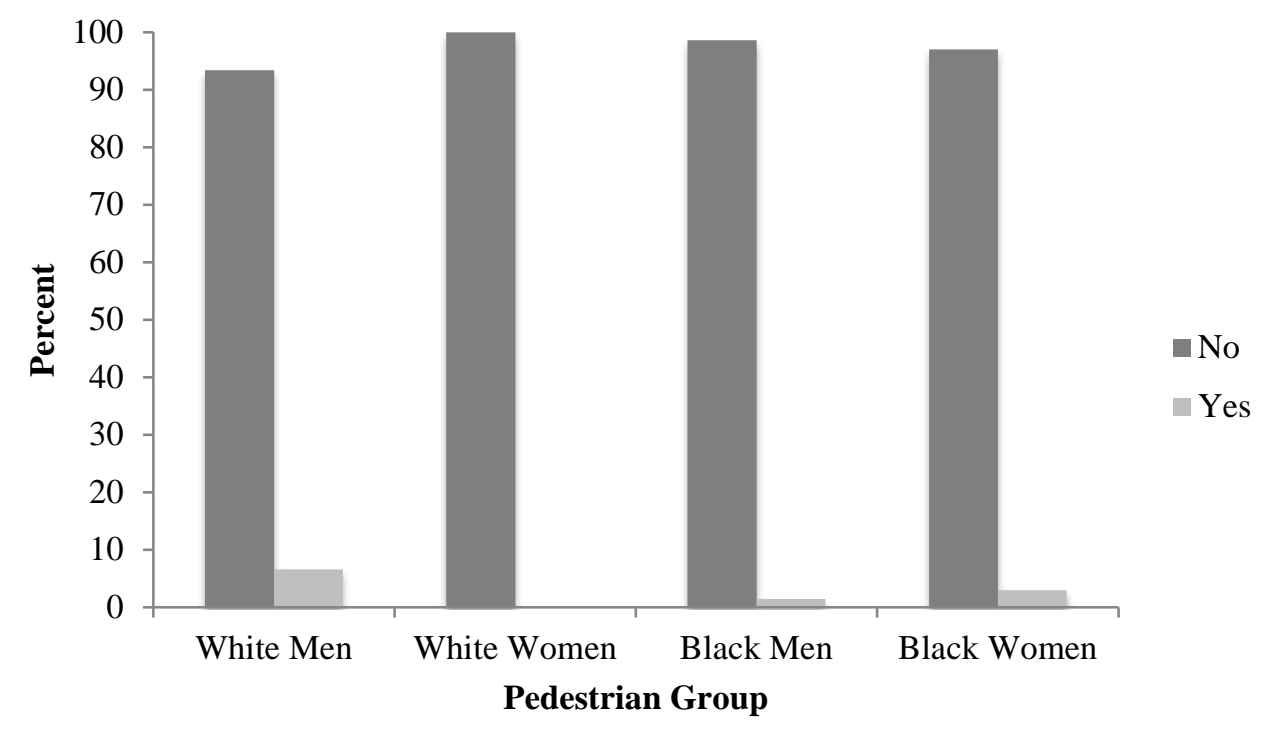

Figure 2.2: Percentage of trials in which the first car stopped for the pedestrian during Phase 1 (unmarked crosswalk) out of 319 total trials.

\subsubsection{Number of cars passing without yielding}

A car stopped in the passing platoon on only 60 of the 319 trials. Of these 60 trials where a car did stop, a 2 (pedestrian race: Black vs. White) X 2 (pedestrian gender: male vs. female) ANOVA was used to test how many cars passed the pedestrian before one yielded; see Figure 2.3. There were no significant main effects of gender $[F(1,55)=.54$, $p=.47]$ and race $[F(1,55)=.00, p=.99]$, nor were interactions found $[F(1,55)=.51$, $p=.48]$. These results indicate that no significant differences were found among White women $(M=7.07, S D=4.29)$, Black women $(M=5.82, S D=6.16)$, White men $(M=7.11$, $\mathrm{SD}=7.77)$, and Black men, $(\mathrm{M}=8.40, \mathrm{SD}=7.40)$ in the number of cars that passed them before one stopped, if there was a car that stopped. 


\section{Cars Passing Without Yielding (unmarked crosswalk)}

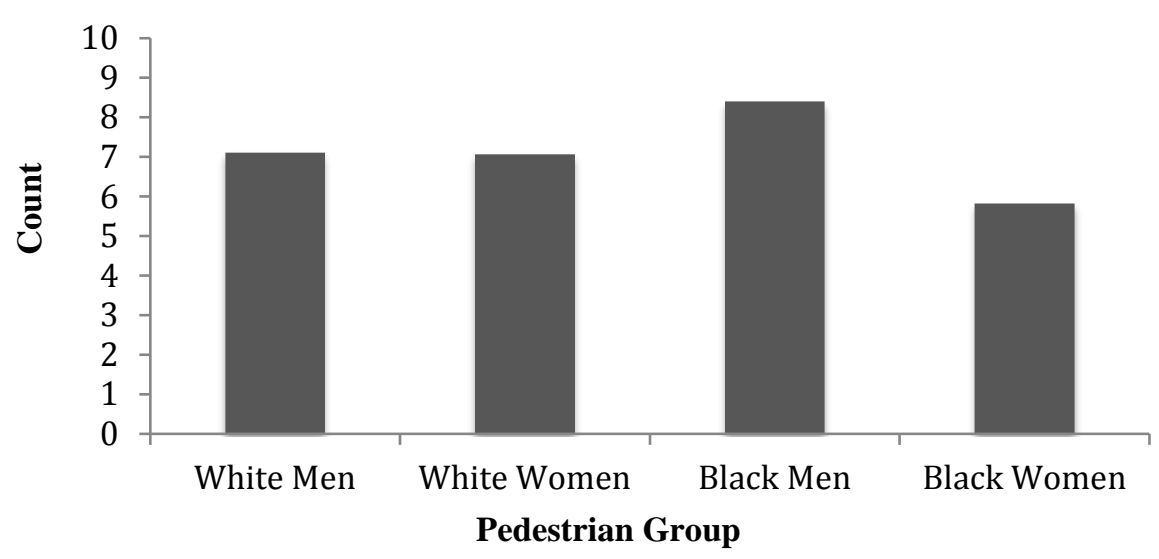

Figure 2.3: Average number of cars that passed without yielding to the pedestrian during Phase 1 (unmarked crosswalk) out of 60 total trials in which a car did stop for the pedestrian.

\subsubsection{Trial length}

A 2 (Pedestrian race: Black vs. white) X 2 (Pedestrian gender: male vs. female) ANOVA was used to examine how long it took for the pedestrian to be able to cross the unmarked crosswalk; see Figure 2.4. Pedestrians waited between 2.35 and 52.00 seconds to cross, either because a car yielded or the full platoon of cars passed without stopping (signaling the end of the trial). Results revealed no significant main effects of gender $[F(1,314)=$ $1.43, p=.23]$ or race $[F(1,314)=.20, p=.65]$, nor was there a significant interaction between gender and race $[F(1,314)=1.19, p=.28]$. This indicates that there was no significant difference in average wait time (in seconds) among White women $(M=28.79$, $\mathrm{SD}=8.02)$, Black women $(\mathrm{M}=28.12, \mathrm{SD}=9.04)$, White men $(\mathrm{M}=26.38, \mathrm{SD}=10.03)$, and Black men, $(\mathrm{M}=28.01, \mathrm{SD}=10.14)$.

\section{Trial Length (unmarked crosswalk)}

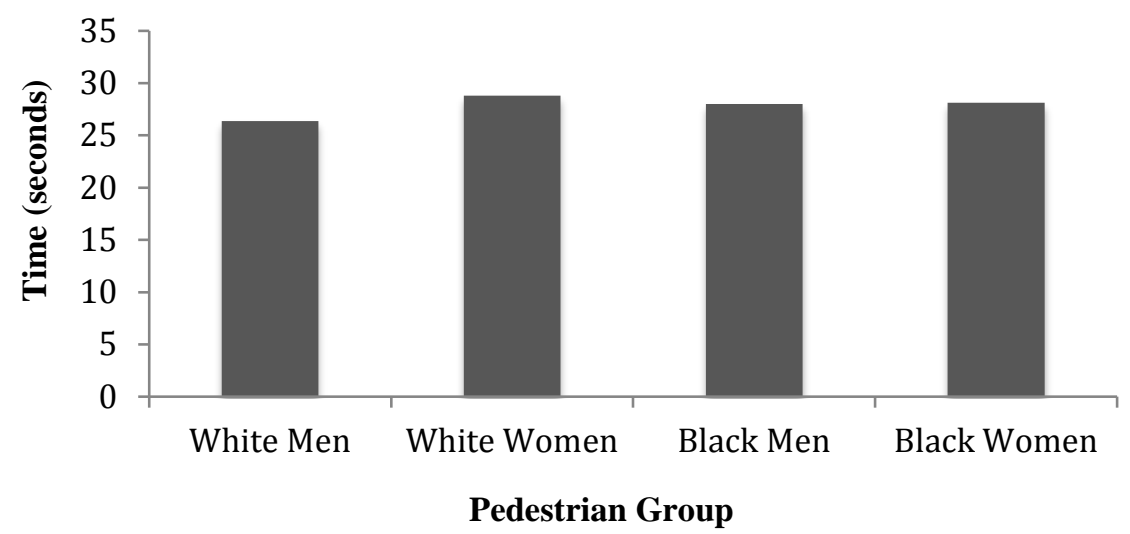

Figure 2.4: Length of trial (in seconds) during Phase 1 (unmarked crosswalk) out of 319 total trials. 


\subsubsection{Driver characteristics}

It was not logistically possible to code the race and gender of all drivers that passed pedestrians. We have this information only about the driver that eventually stopped. Because pedestrians were randomly ordered, drivers should be equally likely to encounter pedestrians for all groups. If drivers that stop for pedestrians are disproportionately found for one group of pedestrians compared to others, it suggests that they may be more likely to stop for this particular group. These results are suggestive, and we recommend they be interpreted as such.

Of the 60 drivers who stopped, 32 were coded as males, 19 were coded females, and 9 were coded as unknown for their gender (coder could not determine). The observed coded race of the drivers that stopped was 48 White, 3 nonwhite, and 9 unknown. For the 60 trials in which a car yielded to the pedestrian at the unmarked crosswalk, we examined whether the drivers' race and gender was related to the pedestrian group for which they stopped. That is, did the drivers' race and gender make it more likely that they stopped for a particular pedestrian group? Neither driver gender, $\chi 2(2, N=52)=1.41, p=.70$, nor driver race, $\chi 2(2, N=52)=1.40, p=.71$, was related to the frequency with which different race and gender pedestrian groups were yielded to. Given the low number of racial minority drivers, and the low number of drivers who stopped overall, these results should be interpreted with caution.

\subsubsection{Phase 1 Conclusions}

The overall non-significant findings from Phase 1 at the unmarked crosswalk indicate that drivers did not differentiate among Black and White men and women at the unmarked crosswalk. That is, each gender and race group had similar experiences attempting to cross at the unmarked crossing. However, this should be interpreted in light of the overall low stopping rates of trials in which any car yielded in a platoon of multiple cars $(\sim 18 \%)$, such that any differences may have been suppressed by a floor effect. Drivers were unlikely to stop for any pedestrian at the unmarked intersection. While Oregon law says that any intersection is a crosswalk, the vast majority of drivers did not yield to the waiting pedestrian at the unmarked intersection, despite their waiting on the curb with indications of waiting to cross. Further, Oregon law requires drivers to stop if a pedestrian is in the roadway. Because of safety concerns, the study pedestrians did not step into the roadway to force compliance, which further allowed drivers to pass the waiting pedestrian.

\subsubsection{Phase 2 Results: Marked Crosswalk}

Phase 2 of the field experiment included 12 new study pedestrians (3 from each race and gender group, ages 18-30, average age 23.0 years) to cross the street at the same intersection that had received a newly marked crosswalk. As before, the pedestrians were all young adults and were perceived to be similar in age across groups. They were again of similar build and clearly identified as members of their race and gender. However, due 
to participant attrition, only one of the Black female pedestrians completed trials $(n=55)$. While data from the Black female pedestrian are included in these analyses (see Coughenour et al., 2017, for similar field experiments using only one pedestrian per group), we suggest caution in its interpretation due to the low sample size from one individual for the Black female group. Because these are different pedestrians in Phase 1 and Phase 2, analyses focus on group differences within each crosswalk type separately, rather than comparing across the marked and unmarked locations for any given pedestrian group.

A total of 485 trials were collected in Phase 2 at the marked crosswalk. Pedestrians crossed in the marked zebra crosswalk. As in Phase 1, trials in which the study pedestrian was joined by another nonstudy pedestrian or bicyclist at the crosswalk $(\mathrm{N}=76)$ were eliminated. The increase in the number of trials excluded during Phase 2 may be due to the greater number of pedestrians attempting to cross this intersection once it became a marked crosswalk. This left a total of 409 trials collected in Phase 2 (129 White female, 110 White male, 115 Black male, 55 Black female). The number of trials completed by each study pedestrian ranged from 23 to 55 .

With the addition of crosswalk markings, a car yielded to a pedestrian in 396 out of 409 trials (96.8\%). This indicates that the installed marked crosswalk was very effective in prompting drivers to stop for pedestrians. Given the higher stopping rates, it is possible that a ceiling effect might mask changes in drivers' stopping behavior based on pedestrian race and gender. See Table 2.1, above, for a complete representation of the results from Phase 2.

\subsubsection{First car stop}

The first car stopped for the pedestrian in 208 out of 380 trials (55\%), demonstrating a sizeable increase in yielding behavior at the same location once the crosswalk was marked. A chi-square was used to determine if these initial stopping behaviors were equitably applied to each type of pedestrian. The test was marginally significant, $\chi^{2}(3$, $\mathrm{N}=380)=6.25, p=.10$; see Figure 2.5. Significant simple effects emerged when pedestrians were categorized by race (collapsing across gender), the White pedestrians more likely to have the first car stop for them (59\% of trials) than the Black pedestrians $(49 \%), \chi^{2}(1, N=378)=3.87, p=.05$. When pedestrians were categorized by gender (collapsing across race), the female pedestrians were more likely to have the first car stop for them $(61 \%)$ than the male pedestrians $(51 \%), \chi^{2}(1, N=378)=4.06, p=.04$. No other significant differences emerged.

Results are consistent if the Black female pedestrian is removed. The chi-square test was significant, $\chi^{2}(2, N=354)=5.93, p=.05$, indicating that stopping rates differed by pedestrian race and gender. Comparing across the three pedestrian groups, simple effects revealed significant differences between the White female and Black male pedestrians, such that White women were more likely to have the first car stop for them (62\% of trials) than Black men, who had a first car stop for them in $46 \%$ of their trials. When pedestrians were categorized by gender (collapsing across race), the female pedestrians 
were more likely to have the first car stop for them (62\%) than the male pedestrians $(47 \%), \chi^{2}(1, N=354)=6.54, p=.01$. When pedestrians were categorized by race (collapsing across gender), the White pedestrians more likely to have the first car stop for them ( $57 \%$ of trials) than the Black pedestrians $(44 \%), \chi^{2}(1, N=354)=5.27, p=.02$.

\section{First car stop (marked crosswalk)}

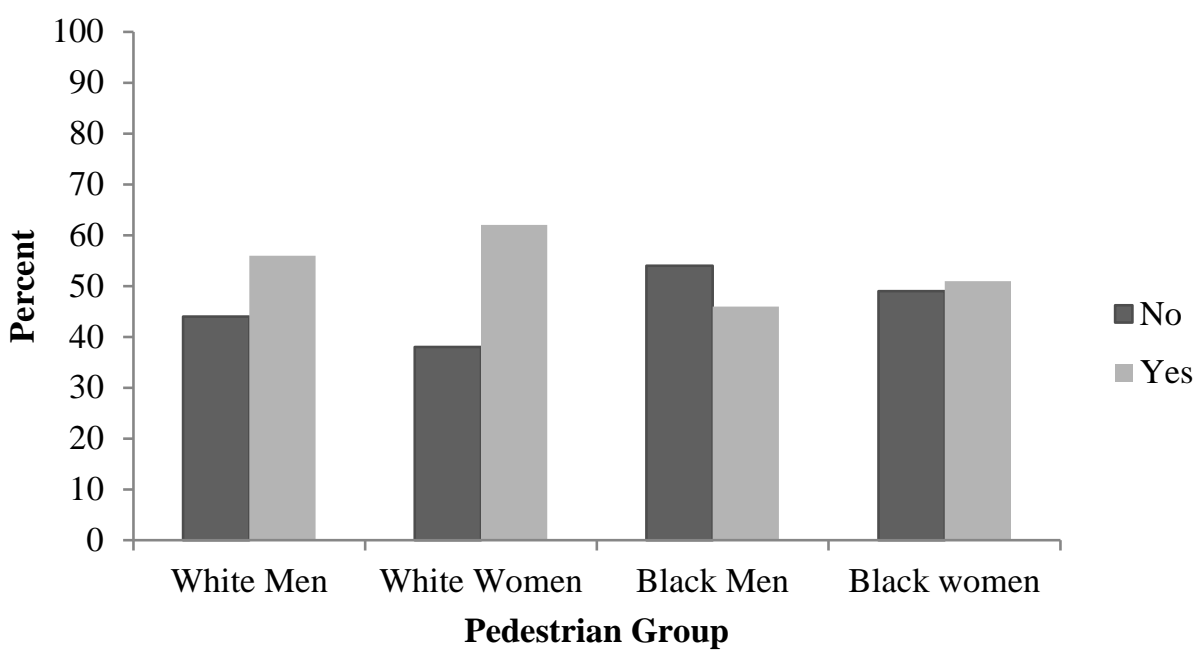

Figure 2.5: Percentage of trials in which the first car stopped for the pedestrian during Phase 2 (marked crosswalk) out of 409 total trials.

\subsubsection{Number of cars passing without yielding}

A car eventually yielded in 396 out of 409 trials (96.8\%) at the marked crosswalk. Of the 396 trials when one did yield, a 2 (pedestrian race: Black vs. white) X 2 (pedestrian gender: male vs. female) ANOVA was used to test how many cars passed the pedestrian before one yielded; see Figure 2.6. Analyses revealed no significant main effects of gender $[F(1,373)=.99, p=.32]$ or race $[F(1,373)=.00, p=.98]$. However, a marginally significant interaction between gender and race was found $[F(1,373)=2.99, p=.09]$, with Black men $(\mathrm{M}=2.05, \mathrm{SD}=3.10)$ being passed by nearly twice as many cars as the Black woman $(\mathrm{M}=1.19, \mathrm{SD}=1.43), t(128.59)=-2.30, p=.02$. There were no differences in the number of cars to pass White men $(\mathrm{M}=1.50, \mathrm{SD}=2.24)$ and White women $(\mathrm{M}=1.73$, $\mathrm{SD}=3.11), t(230)=.65, p=.52$.

When a one-way ANOVA (White men, White women, Black men) was used to test this outcome without the Black female pedestrian, there were no significant differences between pedestrian groups at the omnibus level, $F(2,330)=1.02, p=.36$. 


\section{Cars Passing Without Yielding (marked crosswalk)}

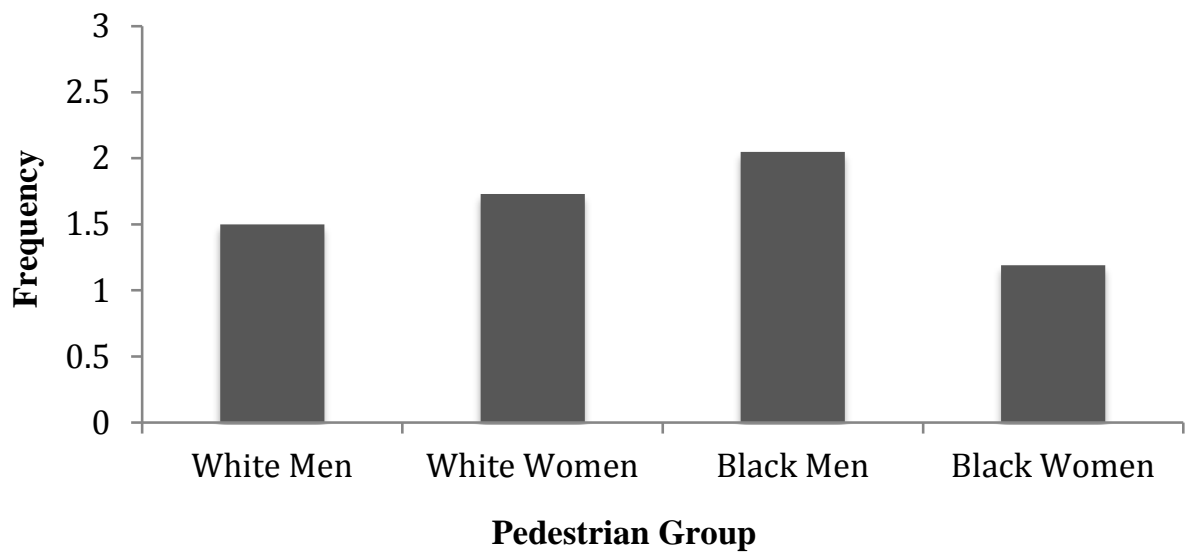

Figure 2.6: Average number of cars that passed without yielding to the pedestrian during Phase 2 (marked crosswalk) out of 396 total trials.

\subsubsection{Trial length}

A 2 (pedestrian race: Black vs. White) X 2 (pedestrian gender: male vs. female) ANOVA was used to examine how long it took for a pedestrian to cross at the marked crosswalk; see Figure 2.7. Pedestrians waited between 1 and 40 seconds to cross at the marked crosswalk, either because a car yielded or the full platoon of cars passed without stopping (signaling the end of the trial). Analyses revealed no significant main effects of gender $[F(1,394)=.21, p=.65]$ or race $[F(1,394)=.03, p=.86]$, nor was there a significant interaction between gender and race $[F(1,394)=.56, p=.46]$. There was no difference in average wait time (in seconds) among White women $(\mathrm{M}=8.79, \mathrm{SD}=8.44)$, White men $(\mathrm{M}=7.74, \mathrm{SD}=6.39)$, Black men, $(\mathrm{M}=8.55, \mathrm{SD}=7.49)$, and the Black woman $(\mathrm{M}=8.32$, $\mathrm{SD}=6.56)$. This pattern is consistent when the Black female pedestrian is excluded, $F(2$, $343)=.34, p=.72$. 


\section{Trial Length (marked crosswalk)}

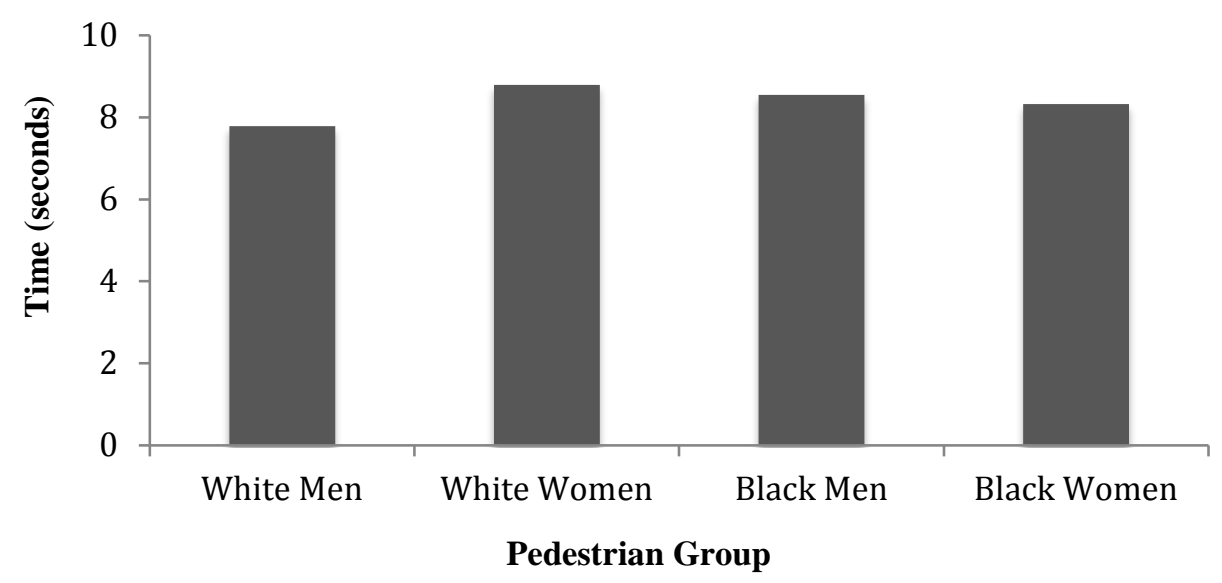

Figure 2.7: Average length of trial (in seconds) during Phase 2 (marked crosswalk) out of 409 total trials in which a car did stop for the pedestrian.

\subsubsection{Driver characteristics}

Of the 396 drivers who stopped for a pedestrian during a trial in Phase 2, 227 were coded as males, 124 were coded as females, and 45 were coded as unknown for their gender, while for race, 250 were coded as White, 34 were coded nonwhite, and 112 were coded as unknown for their race. For these 396 trials, we examined whether the drivers' race and gender were related to the pedestrian group for which they stopped. Neither driver gender, $\chi^{2}(2, \mathrm{~N}=309)=.09, p=.96$, nor driver race, $\chi^{2}(2, \mathrm{~N}=253)=.44, p=.81$, was related to the frequency with which different race and gender pedestrian groups were yielded. The inclusion of the Black female pedestrian did not affect the driver gender $\left[\chi^{2}(3\right.$, $\mathrm{N}=351)=1.27, p=.74]$ or driver race $\left[\chi^{2}(3, \mathrm{~N}=284)=.62, p=.89\right]$ outcomes. Because of the limited diversity in the race of the driver, these results should be interpreted with caution.

\subsubsection{Stop bar}

The stop bar is meant to provide ample space for pedestrians to cross safely. Because it was more than 10 feet away from the intersection, it does not mean that a car stopping past the stop bar was inside the crosswalk. It does indicate that they were stopping closer to the pedestrian than those that stopped behind it and following the sign. When a car did yield and its position could be clearly observed and coded (in 381 trials; the position of the stopped car could not be determined in 14), a chi square test examined whether drivers were obeying the signage by stopping behind the bar on the street when yielding to pedestrians. Significant differences in the position of the stopped car emerged; $\chi^{2}(3$, $\mathrm{N}=381)=21.56, p<.001$, see Figure 2.8. When the pedestrian was a Black male, the cars were more likely to stop after the bar ( $71 \%$ of trials) than before the bar. This indicates that in the majority of trials involving Black men, cars were stopping closer to the 
pedestrian. Similarly, the Black female pedestrian was more likely to have a car stop after the bar (in $67 \%$ of trials) than before it, consistent with the treatment of the Black male pedestrians. However, when the pedestrians were White, the cars were more likely to stop behind the bar (52\% for men, 55\% for women) rather than after it, meaning the cars were farther from the pedestrians. In other words, the stop bar's intended function of creating more space between cars and pedestrians worked most often when pedestrians were White (over half the time), but not when they were Black men (less than a third of the time). When the data for the Black female pedestrian were excluded, the same pattern of results remained, $\chi^{2}(2, \mathrm{~N}=335)=18.64, p<.001$.

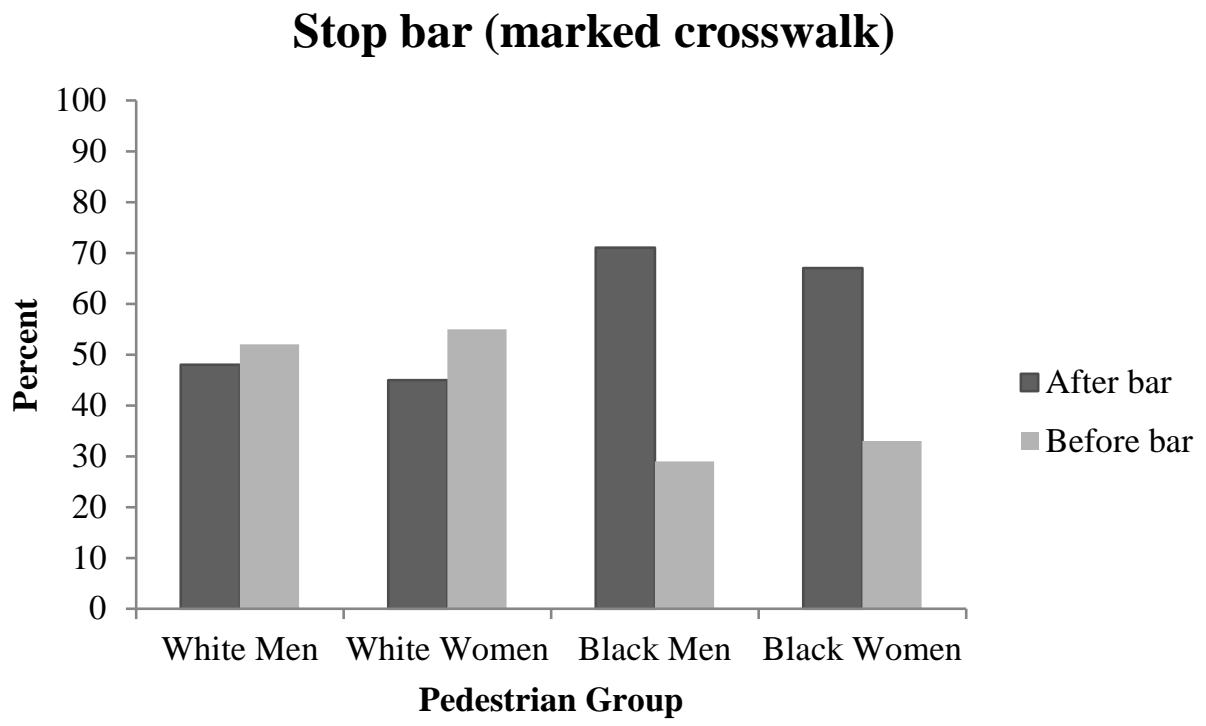

Figure 2.8: Percentage of trials in which cars stopped before or after the stop bar during Phase 2 (at the marked crosswalk) out of 381 total trials in which a car did stop for the pedestrian and its position was recorded.

\subsubsection{Phase 2 Conclusions}

In Phase 2, the presence of a marked crosswalk led to increased stopping for pedestrians, but did not always lead to equitable treatment across groups. The marked crosswalk succeeded in persuading a car in each platoon of traffic to eventually stop for nearly all pedestrians (in $96.8 \%$ of the trials, a car stopped). While there was no significant difference in the time that pedestrians waited to cross the street, race and gender differences did emerge for whether the first car stopped, the number of cars that passed before one yielded, and the positioning of the car that stopped relative to the stop bar. White and female pedestrians were more likely to have the first car stop for them, while Black and male pedestrians were more likely to not have the first car stop for them. Black men were also more likely to have more cars pass them before one stopped. Further, when they did stop, drivers were more likely to stop with their vehicle behind the stop bar when the pedestrian was White, but after the bar when the pedestrian was Black, demonstrating an intrusion into the crossing space for Black pedestrians and a possible safety risk. These patterns occurred regardless of the race and gender of drivers who stopped, suggesting a prevalent bias. 


\subsection{FIELD EXPERIMENT CONCLUSIONS}

Two field experiments tested whether pedestrians' race and gender affected drivers' decision to yield: one when the crossing intersection was unmarked (Phase 1) and one when the crossing intersection was marked (Phase 2). When the crossing intersection was unmarked, drivers' overall compliance in yielding for pedestrians was very low toward all pedestrians waiting to cross the street. On only $18 \%$ of all trials did a car in the platoon eventually yield to the pedestrian, allowing them to cross the street. Once the same intersection received markings and additional signs, drivers' yielding increased dramatically, to $96.8 \%$, for each platoon of traffic (representing one trial). The increase in yielding compliance after the installation of crosswalk marking and signs is consistent with previous research (Zegeer et al., 2005) and professional practice experience. The magnitude of the change, in which yielding rates increased from $18 \%$ to $96.8 \%$ of trials, is significant. This confirms that marking and signing intersections results in higher rates of driver yielding. However, even at the marked crosswalk, the first car to reach the pedestrian stopped only $55 \%$ of the time, indicating that there was still ample perceived discretion in drivers' stopping behavior.

The benefit of increased yielding in the marked crosswalk, however, may not be equitably distributed. While no pedestrian race and gender differences were found to affect drivers' stopping behavior at the unmarked intersection, primarily due to the low overall stopping rates, differences did emerge at the marked crosswalk. Drivers were less likely to stop for Black and male pedestrians than for White and female pedestrians.

Furthermore, how drivers yield may be different depending on the pedestrians' race, such that they when they do decide to stop, they do so closer to Black pedestrians. This infringement on the crosswalk space for Black pedestrians can carry with it with potential safety implications. It is possible that this infringement can also affect crash rates, playing a part in the disproportionate pedestrian fatality rates for racial minorities. Further, the intrusion into a pedestrian's space may negatively affect the pedestrian's experience walking, and result in changes in people's choice to walk or how they cross the street. We follow up on this theme in the subsequent focus groups to further probe this issue.

This biased stopping pattern based on pedestrian race is consistent with contemporary forms of racial bias that are more subtle and nuanced in nature (Dovidio, 2001). Although it was not possible to directly measure drivers' psychological attitudes in this study, these results are in line with other outcomes of implicit bias, which occurs beneath conscious awareness and is pervasive across society and groups (Greenwald and Banaji, 1995; Greenwald et al. 2009). Implicit biases are more likely to influence behavior under conditions in which quick decisions are made, there are distractions and attention might be diverted (Fazio and Olson, 2003), which are characteristic of the driving task. Drivers may be unaware that they hold these implicit associations based on race and also be unaware that they can influence their decisions to stop for pedestrians. Because they are unconscious, they are also more difficult and require different routes to reduce than traditional explicit forms of racism or prejudice. Further, people from all groups (e.g., 
race, gender, age) can hold implicit associations due to their exposure to cultural group stereotypes in society (Greenwald et al., 2009), which is consistent with the study finding that stopping decisions were not affected by the drivers' race or gender (although caution is noted on this finding, given the low number of racial minority drivers in the sample). Further research is needed to directly test the causal relationship between drivers' psychological attitudes and their stopping decisions, and pinpoint the role that implicit and explicit racial beliefs play in this process.

In Oregon, every intersection is a crosswalk, with or without additional markings. The Oregonian Crossing campaign seeks to educate Oregonians on this issue through media campaigns; see Figure 2.9 as an example.

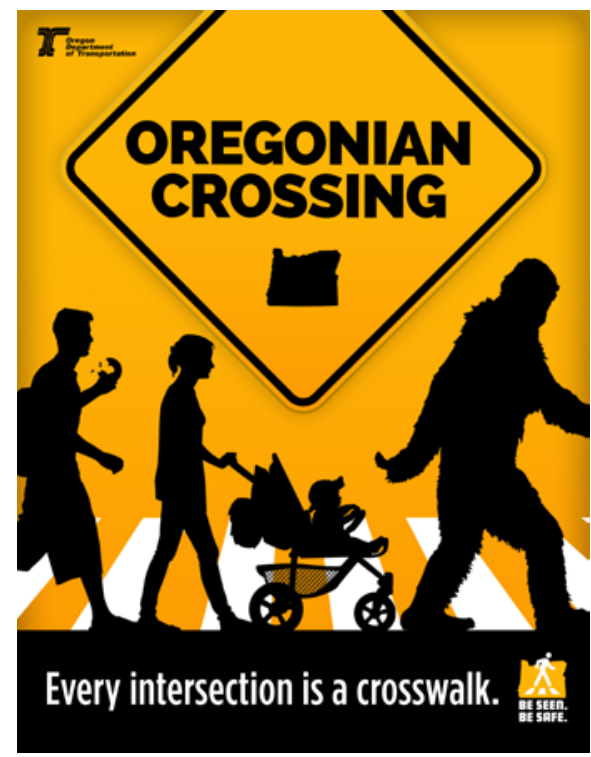

Figure 2.9: Educational material from Oregonian Crossing Campaign to promote awareness that every intersection is a crosswalk.

However, it is clear from Phase 1 of our study that most drivers passing through Southeast $14^{\text {th }}$ Avenue on Belmont Street did not stop for pedestrians at the unmarked intersection. Crosswalk markings and signs, however, are more universally understood as requiring a driver to yield to a pedestrian trying to cross the street, as evidenced by Phase 2 results. Perhaps as a result, the number of pedestrians crossing at this location increased after the crosswalk was signed and marked (as suggested by the increase in number of times a nonstudy pedestrian or cyclist joined the waiting study pedestrian during Phase 2 ). Without controlling for confounding factors like changes in nearby land uses, this suggests that pedestrians may be aware of drivers' increased likelihood of stopping if the crosswalk is marked. Future research could examine whether these were new walking trips or route choices by intercepting pedestrians after the installation of a new marked crossing and asking about their travel behaviors before and after the installation. 


\subsection{FOCUS GROUPS}

\subsection{PURPOSE}

The controlled field experiment provided quantitative evidence of racial and gender disparities at crosswalks. To complement these findings, three focus groups were conducted to better understand Black and African Americans' lived experiences and perspectives as pedestrians in Portland, focusing on their interactions with drivers and at crosswalks. We wanted to see if their experiences matched the quantitative results and if they perceived differential treatment as pedestrians.

Focus groups bring people together to discuss an issue of interest to researchers, making use of group dynamics to encourage participants to share their perceptions and experiences around the topic of study (Krueger, 2000). Although not as widely utilized as surveys in existing transportation research, focus groups can invoke the social interactions found between roadway users (Musselwhite et al., 2010) in an environment that is both easy and safe to create and observe in a way that field observations or experiments are not.

As a qualitative method, focus groups provide the opportunity to collect rich, contextspecific information about the topic, without overly constraining the boundaries based on initial hypotheses. The qualitative approach of focus groups allows researchers to explore not only the what of people's opinions, but also the how and why (Morgan, 1997). In addition, focus groups present an opportunity to go beyond attitudes and opinions to include participant experiences and behaviors, albeit self-reported ones (Morgan, 1997, pg. 20).

\subsection{RECRUITMENT}

Several recruitment tactics were used to locate participants of the Black and African American community for these focus groups. Flyers were created and posted at the Portland State University campus and in various locations around Portland. An email describing the study was distributed on several community groups and listservs. The focus groups were co-sponsored by Oregon Walks, a nonprofit advocacy organization, dedicated to promoting walking for everyone, that aided by distributing the study announcement to their members.

People who were interested in participating were invited to email the research team. Upon doing so, they were asked to complete a short screening form (Appendix E). All respondents who indicated that they were Black/African American, had lived in the Portland metropolitan area for at least one year, and regularly walked to places in Portland were invited to participate.

A total of 12 Black and African American people participated across the three focus groups. Of these 12 participants, 10 self-identified as women, 1 as a man, and 1 as a 
trans-man. Their ages ranged from 20 to 46 years old, and averaged approximately 29 years old, with seven in their 20s, four in their 30s, and one in their 40s. They had each lived in the Portland metropolitan area between 4 and 27 years, with an average around 16 years, and reported walking on average 12 hours per week. Most said they walked to work or school, with exercise and errands being other common reasons.

\subsection{PROCEDURE}

Three focus groups were held in April 2017. Two sessions took place on the Portland State University campus and the third at a community organization's space in North Portland. Once participants arrived for a focus group, they were greeted by a research assistant who asked them to read and sign a consent form and make a nametag. They were then seated around a large table, with the focus group moderator at the head. Snacks were provided.

NW CART + Captioning LLC provided on-site, live transcription services. The transcriber was seated in the corner of the room, in view of participants but out of the way of the group members. The focus groups were also audio recorded. Participants' names were changed to numbers for the transcription in order to provide anonymity.

The focus groups began with the moderator introducing herself and the general purpose of the study. Participants were encouraged to speak candidly about their positive and negative experiences as pedestrians in Portland, and were assured of their confidentiality.

The interview guide is provided in Appendix F. Focus groups are a purposive group interaction around a topic of interest, therefore the research questions should drive the selection of potentially “information-rich" questions (Krueger, 2000). The first question about where people walk was intended to get participants talking and thinking generally about walking in Portland. Because the focus group was advertised as being about experiences of walking in Portland as a person of color, the next question was intended to hear from participants about that topic - in whatever format and on whatever aspect of walking they wished to discuss. This set up allows participants to be heard on any topic before turning to the research-focused questions about issues of driver treatment and potentially racially-biased yielding. This first research-focused question was open-ended, in order to achieve the wide end of the interview "funnel" (Morgan, 1997). The next question asked participants to focus first on positive experiences and then on negative ones.

As the question funnel narrowed, participants were guided to more specific areas of research interest, specifically about drivers' yielding behavior and whether it was perceived to be racially-biased. The moderator then shared information about previous findings about drivers’ biased yielding in Portland (Goddard, Kahn, \& Adkins, 2015), and asked participants to respond to this information. Finally, participants were given a chance to offer final thoughts or opinions more generally, in order to provide additional qualitative data about which issues people feel most strongly. 
Each focus group took place over two hours. Once the focus group had completed, participants received \$30 for compensation.

For the purposes of this report, we focus on participants' perceptions of the ways in race impacted their experiences as pedestrians, in order to see if the results from the objective field study matched their experiences. While a full qualitative analysis is currently ongoing, we report initial findings most closely related to the field experiment here.

The research team analyzed the focus groups transcripts to explore the extent to which interactions with drivers were perceived to be influenced by race or bias and looked for additional recurring themes. Members of the research team read through the transcripts multiple times and highlighted consistent themes, which were then discussed and agreed upon as a group. Several additional themes were identified through this process. Each of these is discussed in detail below.

\subsection{FINDINGS}

The participants of the three focus groups provided rich information about their experiences walking around Portland, and specifically interacting with drivers when trying to cross the street. The results echoed findings from the field experiment.

Black and African American participants from each of the three focus groups not only reported that their interactions with drivers were perceived to be affected by race, but also observed that this was made evident by the different treatment of White pedestrians nearby or walking with the participant. For example, one participant noted that:

"I will come to an intersection on one side and waiting because there's cars, and then as soon as a white person steps on the other side, oh, car stops. I'm like, this is magic, what's going on? It was you. It wasn't me."

Another participant described a situation where walking with a White partner resulted in more cars stopping:

I haven't thought about, like, my identities as I'm crossing the street. I-no, I do, because when I had a white partner they would stop a lot more often than when I was by myself or with a black person. So, yes, race has something to do with it. They don't see us like human beings like they are. They think that we're second-class citizens, so when I'm crossing the street I do see a lot more negative experiences and they don't want to be inconvenienced or stop when they are supposed to. That's why we always get hit and they get upset.

Participants perceived a sense that drivers, particularly White drivers, were dismissive of their value or right to be in the street as a pedestrian:

I walk everywhere. I take public transportation. I think that there's this, you know, understanding of that for drivers especially, like, white drivers, white 
male drivers and there's this kind of subconscious, like, this person isn't important, so I can rush them through while they are trying to cross the street or whatever. You know, I don't have to be as, like, attentive or whatever. And it's probably not something that they actually acknowledge, but it happens all the time.

Another added:

It's normally white women who do this and they are like, I'm sorry. If you were really sorry, you wouldn't be in the crosswalk in my way.

While these statements were not made by every focus group participant, there did seem to be widespread agreement, either verbally through additional stories or with verbal and non-verbal group affirmation. This affirmation manifested itself clearly when the moderator shared the results of our previous crosswalk study (Goddard et al., 2015) with focus group participants later in the discussion. Participants agreed that these results matched their experiences and they were not surprised by the findings. One of the participants had previously heard of the study and shared the following reaction:

When we saw the study, my mom was like, duh, why did they have to do that? It kind of goes-we understand the point of surveys and stuff, but it's, like, one of the things it's, like, you did the surveys, but you could have asked black people and black people would have told you yes, and you could believe them because that shit happens.

Several respondents discussed problems with drivers' stopping in the crosswalk, which echoed the field experiment findings (Section 2.6.2.5 above) about infringement into the crossing space. One participant shared that this infringement causes frustration, stating,

"I think for me, it's because of how these things intersect with our identities, mine's and whoever it is doing it to me. I think the most irritating one is when cars are, like, in the crosswalk and then like they will like roll down their window and say, my God, I'm sorry. I'm so sorry. I'm so sorry. And I'm like looking at them if you were sorry you wouldn't be rolling down your window, you would be hitting reverse and backing the fuck up. So, like, you are not really sorry."

Another participant described how a driver's infringement into the crosswalk caused them to show their frustration, saying

"I know when cars are in the crosswalk, it pisses me off, like, when you say you touch their car. I will get close and look at you. Sometimes they say sorry, and sometimes they will give me a stank look. Like, you are not going 
to give me a stank look. You are in the wrong. I agree. You feel like you have to hurry. I'm a driver and a walker.”

Participants repeatedly noted the feeling that drivers valued their own time or life more than pedestrians, even to the point of hitting someone in their hurry to get somewhere. One participant shared a personal experience of being hit, saying

"Especially, like, when you are stopping in the crosswalk, that's inconvenience. You were trying to rush across the street. And when I got hit by a car, they were rushing to go pick up somebody. And it was, like, oh, so my life wasn't valuable, and you just hit me. So, yeah, I'm inconvenienced or disrespected."

Black and African American participants reported the stress of these racially charged interactions as similar to other experiences as a racial minority. One person shared that

"I think it's stressful. It's just an added stress to your commute whenevereven when it's a leisurely commute. Stuff like that it's, like, you just have to, you know, I guess, just part of the black experience of being more aware and cautious of everything that we do."

Another indicated how these experiences impact them as pedestrians, causing them to change their behavior:

“ I always think about it. I'm, like, I'm not going to run across the street because I feel, like, they want me to get out of the way. I don't want conflict. I don't like conflict. So I, like, submit and run across the street and get out of their way. I shouldn't have to do that. I have the right-of-way. I have the light. It's my turn to walk. You know the traffic rules."

Participants did make a point to share that, despite their negative experiences, that walking in Portland was sometimes positive, too, particularly relative to other places they had been. One participant stated that

"Even though I had some negative experiences, I would say that, like, Portland for me is one of the best cities to walk in. Like, I have lived and visited other places and it's, you know, despite some of these negative experiences, it's still one of the best. You know, even though I'm super-cautious as a woman walking, at night especially, nothing has happened to me here. Like, or, like, I don't know. It's just like it's really safe. I used to live in Anchorage, Alaska, not safe at all for pedestrians. I have family in L.A. and I visit them all the time, not safe for pedestrians. And, like, Portland is not bad and I think that I, like, mentally got stuck on some negative thoughts about things I have experienced as a pedestrian here, but overall, it's been great." 


\subsection{FOCUS GROUP CONCLUSIONS}

Conducting focus groups complemented the field experiment by providing richer, more nuanced details of the experiences of Black and African American people who walk in Portland. The discussion was highly consistent across all three focus groups, and in line with the findings of the systematic field experiment examining drivers' behaviors in a naturalistic setting. Even though Black and African American participants were first asked about positive experiences, most of the discussion centered on negative experiences, of which participants had many. The vast majority of the overall discussion across all three focus groups was on negative experiences, indicating that these experiences are salient and frequent. Participants reported a heightened sense of the difficulties and dangers posed by negative interactions with drivers as pedestrians, which they also often attributed to their race. Their race was often brought up on their own, before specific questions about the field experiment. There was also a clear understanding of how crosswalk markings and pedestrian signals are intended to affect driver behavior by encouraging stopping, although several participants expressed skepticism that marking crosswalks will keep drivers from racially-biased behaviors. This concern is consistent with the findings from Phase 2 of the field experiment, in which marking the crosswalk increased overall yielding behavior, but did so differentially for White and Black pedestrians.

Portland's overall investment in pedestrian infrastructure and pedestrian friendly environment is noticed and appreciated by the focus group participants. The challenge, however, is to make these pedestrian experiences equally accessible and safe to all. 


\subsection{OVERALL RECOMMENDATIONS}

As is evident from these study results, marking an intersection increases drivers' yielding behavior. Therefore, at locations in which the City wants to immediately increase driver yielding, it is clear that marking and signage can result in significant change. However, it is also clear that these yielding behaviors are not equally applied to all pedestrians. Although overall compliance increases when the crosswalk is marked, drivers still perceive that stopping is discretionary and not required. It is this perceived discretion that makes drivers feel able to choose to stop for some pedestrians but not for others. Therefore, in order to reduce this disparate stopping behavior, it is recommended that increased and additional signage can be employed to help reduce driver discretion and make stopping register more as mandatory. This additional infrastructure change might include installing flashing lights at crosswalk locations, additional signals indicating a crosswalk ahead and sidewalk designs to make pedestrians more visually prominent (e.g., curb extensions). Our findings also demonstrated that when a driver did stop, they stopped closer to-past the stop bar for-Black pedestrians. Additional painted markings on the ground might further highlight the existence of the stop bar, and flashing or lighted signs can also relate the need to stop behind the bar. In addition to these infrastructural changes, media awareness campaigns can focus on the need to stop for all pedestrians. Finally, stricter enforcement of drivers' yielding behaviors at crosswalks can also help reduce perceived discretion and promote more equitable yielding. We further recommend additional focus groups with disadvantaged community members to discuss these issues and ways to reduce the disparities they encounter. In summary, changes should focus on reducing drivers' perceived discretion in stopping behavior at crosswalks, which will lead to more stopping overall for all pedestrian groups. 


\subsection{LIMITATIONS}

Various limitations to the reported studies are worth noting. First is the fact that, due to participant attrition, only one Black female completed the trials in Phase 2 of the field experiment. The other race and gender groups had three pedestrians each, making their estimates more reliable. As noted earlier, other field experiments have employed only one pedestrian per group (Coughenour et al., 2017); however, we still suggest caution in the interpretation. Second, the low number of racial minority drivers in the study limits the ability to draw strong conclusions about the role of driver characteristics on yielding behavior. Next, the studies were conducted in Portland, Oregon, and therefore may be specific to this local context. If implicit biases are leading to these differences in stopping decisions, the results should generalize beyond Portland, but additional research in different contexts is needed to establish this point. Next, the focus on these studies has been on the experiences of Black and African American pedestrians. Additional research is needed to see if these patterns generalize to other racial minority groups in the United States, such as Latinos and Asian Americans. We discuss additional future directions for research to address these limitations and other extensions next. 


\subsection{FUTURE DIRECTIONS FOR RESEARCH}

Results from the field experiment and focus groups indicate that Black pedestrians face discrimination at marked crosswalks, leading to potentially unsafe crossing experiences. This research is consistent with prior studies (Coughenour et al., 2017; Goddard et al., 2015) finding similar racial discrimination against pedestrians. In the systematic field experiments, examining the effects of crosswalk signs and marking on driver's yielding behavior at the same location demonstrated that a) signs and marking significantly increase driver compliance with crossing rules or expectations, and b) that increase in compliance may not be equitably distributed. Specifically, drivers were less likely to yield and more likely to infringe into the space of Black pedestrians. Focus groups of Black and African American pedestrians largely echoed these same concerns, centering on negative experiences as pedestrians that were often attributed to their race and influenced the decisions to walk in the future.

These findings suggest several potential transportation- and psychology-related future research directions, including:

1. Does racially biased yielding result in greater likelihood of drivers' hitting, injuring, or killing pedestrians of color?

2. Does infringement into pedestrian space have negative safety outcomes for pedestrians of color?

3. Does infringement into pedestrian space or the overall racially biased interactions between drivers and pedestrians significantly affect people's choice of whether to walk, or walking routes?

4. Can additional signs and markings remove the racial effects of driver yielding?

5. Are the qualitative experiences of pedestrians of color in Portland similar to the experiences of pedestrians of color in other U.S. cities?

6. Can enforcement improve driver yielding without increasing negative effects on pedestrians of color?

7. Are implicit or explicit biases influencing drivers' decisions to stop for pedestrians based on race?

8. Can reducing implicit biases improve drivers' decisions to stop for all pedestrians?

9. How do neighborhood location and city demographics influence drivers’ stopping behavior based on pedestrian race and gender?

10. How do drivers treat other non-Black racial minorities (e.g., Latinos, Asians)?

Future research should address these questions, as well as others, to better understand and remediate the effects of drivers' disparate stopping behaviors based on pedestrian race and gender. It is recommended that future research employs a variety of methodologies, including naturalistic observation studies, field experiments to assess causality, survey measures, and in-depth focus groups and interviews with pedestrians to gain deep insight into their personal experiences. From this combination of methods and research studies, more targeted interventions can be executed to improve equitable pedestrian experiences and promote safe walking among city residents. 


\subsection{REFERENCES}

Centers for Disease Control and Prevention. 2013. "Motor Vehicle Traffic-Related Pedestrian Deaths-United States, 2001-2010.” Morbidity and Mortality Weekly Report 62, No. 15.

Coughenour, Courtney, Sheila Clark, Ashok Singh, Eudora Claw, James Abelar and Joshua Huebner. 2017. "Examining racial bias as a potential factor in pedestrian crashes.” Accident Analysis \& Prevention 98: 96-100. doi:10.1016/j.aap.2016.09.031.

Dovidio, John F. 2001. "On the nature of contemporary prejudice: The third wave.” Journal of Social Issues 57, No. 4: 829-849.

Fazio, Russell H., and Michael A. Olson. 2003. "Implicit measures in social cognition research: Their meaning and use.” Annual Review of Psychology 54, No. 1: 297-327.

Goddard, Tara, Kimberly Kahn and Arlie Adkins. 2015. "Racial Bias in Driver Yielding Behavior at Crosswalks.” Transportation Research Part F: Traffic Psychology and Behaviour 33: 1-6. doi:10.15760/trec.130.

Goff, Phillip Atiba, and Kimberly Barsamian Kahn. 2013. "How psychological science impedes intersectional thinking.” Du Bois Review: Social Science Research on Race 10, No. 02: 365-384.

Greenwald, Anthony G., and Mahzarin R. Banaji. 1995. "Implicit social cognition: attitudes, self-esteem, and stereotypes.” Psychological Review 102, No. 1: 4-27.

Greenwald, Anthony G., T. Andrew Poehlman, Eric Luis Uhlmann and Mahzarin R. Banaji. 2009. "Understanding and using the Implicit Association Test: III. Meta-analysis of predictive validity.” Journal of Personality and Social Psychology 97, No. 1: 17-41.

Harrell, W. Andrew. 1992. "Driver response to a disabled pedestrian using a dangerous crosswalk.” Journal of Environmental Psychology 12, No. 4: 345-354.

Johnson, Randal S. 2005. Pedestrian safety impacts of curb extensions: a case study. No. FHWA-OR-DF-06-01.

Krueger, R. A. (2000). Focus groups : a practical guide for applied research (3rd ed.). Thousand Oaks, Calif: Sage Publications.

Morgan, D. L. (1997). Focus groups as qualitative research (2nd ed.). Thousand Oaks, Calif: Sage Publications.

National Highway Traffic Safety Administration. 2009. "Traffic safety facts: 2007 data: pedestrians.” Annals of Emergency Medicine 53, no. 6: 824. 
Nosek, Brian A., Frederick L. Smyth, Jeffrey J. Hansen, Thierry Devos, Nicole M. Lindner, Kate A. Ranganath, Colin Tucker Smith et al. 2007. "Pervasiveness and correlates of implicit attitudes and stereotypes.” European Review of Social Psychology 18, no. 1: 36-88.

Piff, Paul K., Daniel M. Stancato, Stéphane Côté, Rodolfo Mendoza-Denton and Dacher Keltner. 2012 "Higher social class predicts increased unethical behavior." Proceedings of the National Academy of Sciences 109, No. 11: 4086-4091.

Rosenbloom, Tova, Dan Nemrodov and Adar Ben Eliyahu. 2006. "Yielding behavior of Israeli drivers: interaction of age and sex.” Perceptual and Motor Skills 103, No. 2: 387390.

Sidanius, Jim, and Felicia Pratto. 2001. Social dominance: An intergroup theory of social hierarchy and oppression. Cambridge University Press.

Van Houten, Ron, and Louis Malenfant. 1992. "The influence of signs prompting motorists to yield before marked crosswalks on motor vehicle-pedestrian conflicts at crosswalks with flashing amber.” Accident Analysis \& Prevention 24, No. 3: 217-225.

Zegeer, Charles V., J. Richard Stewart, Herman H. Huang, Peter A. Lagerwey, John Feaganes and B. J. Campbell. 2005. Safety effects of marked versus unmarked crosswalks at uncontrolled locations: Final report and recommended guidelines. No. FHWA-HRT$04-100$. 


\subsection{APPENDICES}

\section{APPENDIX A: Primary trial coding form}

\begin{tabular}{|l|l|llll|l|}
\hline Trial \# & Ped \# & \multicolumn{3}{|l|}{ Ped Gender and } & Notes/comments \\
& & Race & & \\
\hline & & M & F & B & W & \\
\hline & & M & F & B & W & \\
\hline & & M & F & B & W & \\
\hline & & M & F & B & W & \\
\hline & M & F & B & W & \\
\hline & & M & F & B & W & \\
\hline & & M & F & B & W & \\
\hline & & M & F & B & W & \\
\hline & M & F & B & W & \\
\hline & & M & F & B & W & \\
\hline & M & F & B & W & \\
\hline & & M & F & B & W & \\
\hline & & M & F & B & W & \\
\hline & M & F & B & W & \\
\hline & & M & F & B & W & \\
\hline & & M & F & B & W & \\
\hline & & M & F & B & W & \\
\hline & & M & F & B & W & \\
\hline & & M & F & B & W & \\
\hline & & M & F & B & W & \\
\hline & M & F & B & W & \\
\hline & M & F & B & W & \\
\hline & M & F & B & W & \\
\hline & M & F & B & W & \\
\hline & M & F & B & W & \\
\hline & M & F & B & W & \\
\hline & M & F & B & W & \\
\hline & M & F & B & W & \\
\hline & M & F & B & W & \\
\hline & M & F & B & W & \\
\hline & M & F & B & W & \\
\hline & M & F & B & W & \\
\hline & M & F & B & W & \\
\hline & M & F & B & W & \\
\hline & M & F & B & W & \\
\hline & & & & & & \\
\hline & & & & & & \\
\hline & & & &
\end{tabular}




\section{APPENDIX B: Timing coding sheet}

\begin{tabular}{|c|c|c|c|}
\hline Trial \# & $\begin{array}{l}\text { Length of trial until car } \\
\text { stopped/yielded (sec) }\end{array}$ & Trial \# & $\begin{array}{l}\text { Length of trial until car } \\
\text { stopped/yielded (sec) }\end{array}$ \\
\hline & & & \\
\hline & & & \\
\hline & & & \\
\hline & & & \\
\hline & & & \\
\hline & & & \\
\hline & & & \\
\hline & & & \\
\hline & & & \\
\hline & & & \\
\hline & & & \\
\hline & & & \\
\hline & & & \\
\hline & & & \\
\hline & & & \\
\hline & & & \\
\hline & & & \\
\hline & & & \\
\hline & & & \\
\hline & & & \\
\hline & & & \\
\hline & & & \\
\hline & & & \\
\hline & & & \\
\hline & & & \\
\hline & & & \\
\hline & & & \\
\hline & & & \\
\hline & & & \\
\hline & & & \\
\hline & & & \\
\hline & & & \\
\hline & & & \\
\hline
\end{tabular}


APPENDIX C: First Stop, Number Passed, Stop Bar coding sheet

\begin{tabular}{|c|c|c|c|c|}
\hline Trial \# & $\begin{array}{l}\text { First car } \\
\text { stop? }\end{array}$ & $\begin{array}{l}\text { \# of cars passing } \\
\text { w/o stopping }\end{array}$ & Position of car th & stopped \\
\hline & $\mathrm{Y} \quad \mathrm{N}$ & & Before stop bar & After stop bar \\
\hline & $\mathrm{Y} \quad \mathrm{N}$ & & Before stop bar & After stop bar \\
\hline & $\mathrm{Y} \quad \mathrm{N}$ & & Before stop bar & After stop bar \\
\hline & $\mathrm{Y} \quad \mathrm{N}$ & & Before stop bar & After stop bar \\
\hline & $\mathrm{Y} \quad \mathrm{N}$ & & Before stop bar & After stop bar \\
\hline & $\mathrm{Y} \quad \mathrm{N}$ & & Before stop bar & After stop bar \\
\hline & $\mathrm{Y} \quad \mathrm{N}$ & & Before stop bar & After stop bar \\
\hline & $\mathrm{Y} \quad \mathrm{N}$ & & Before stop bar & After stop bar \\
\hline & $\mathrm{Y} \quad \mathrm{N}$ & & Before stop bar & After stop bar \\
\hline & $\mathrm{Y} \quad \mathrm{N}$ & & Before stop bar & After stop bar \\
\hline & $\mathrm{Y} \quad \mathrm{N}$ & & Before stop bar & After stop bar \\
\hline & $\mathrm{Y} \quad \mathrm{N}$ & & Before stop bar & After stop bar \\
\hline & $\mathrm{Y} \quad \mathrm{N}$ & & Before stop bar & After stop bar \\
\hline & $\mathrm{Y} \quad \mathrm{N}$ & & Before stop bar & After stop bar \\
\hline & $\mathrm{Y} \quad \mathrm{N}$ & & Before stop bar & After stop bar \\
\hline & $\mathrm{Y} \quad \mathrm{N}$ & & Before stop bar & After stop bar \\
\hline & $\mathrm{Y} \quad \mathrm{N}$ & & Before stop bar & After stop bar \\
\hline & $\mathrm{Y} \quad \mathrm{N}$ & & Before stop bar & After stop bar \\
\hline & $\mathrm{Y} \quad \mathrm{N}$ & & Before stop bar & After stop bar \\
\hline & $\begin{array}{ll} \\
\end{array}$ & & Before stop bar & After stop bar \\
\hline & $\mathrm{Y} \quad \mathrm{N}$ & & Before stop bar & After stop bar \\
\hline & $\mathrm{Y} \quad \mathrm{N}$ & & Before stop bar & After stop bar \\
\hline & $\mathrm{Y} \quad \mathrm{N}$ & & Before stop bar & After stop bar \\
\hline & $\mathrm{Y} \quad \mathrm{N}$ & & Before stop bar & After stop bar \\
\hline & $\mathrm{Y} \quad \mathrm{N}$ & & Before stop bar & After stop bar \\
\hline & $\mathrm{Y} \quad \mathrm{N}$ & & Before stop bar & After stop bar \\
\hline & $\begin{array}{ll}\mathrm{Y} & \mathrm{N} \\
\end{array}$ & & Before stop bar & After stop bar \\
\hline & $\mathrm{Y} \quad \mathrm{N}$ & & Before stop bar & After stop bar \\
\hline & $\mathrm{Y} \quad \mathrm{N}$ & & Before stop bar & After stop bar \\
\hline & $\mathrm{Y} \quad \mathrm{N}$ & & Before stop bar & After stop bar \\
\hline & $\mathrm{Y} \quad \mathrm{N}$ & & Before stop bar & After stop bar \\
\hline & $\mathrm{Y} \quad \mathrm{N}$ & & Before stop bar & After stop bar \\
\hline & $\mathrm{Y} \quad \mathrm{N}$ & & Before stop bar & After stop bar \\
\hline & $\mathrm{Y} \quad \mathrm{N}$ & & Before stop bar & After stop bar \\
\hline & $\begin{array}{ll}\mathrm{Y} & \mathrm{N} \\
\end{array}$ & & Before stop bar & After stop bar \\
\hline & $\mathrm{Y} \quad \mathrm{N}$ & & Before stop bar & After stop bar \\
\hline & $\begin{array}{ll}\mathrm{N} \\
\end{array}$ & & Before stop bar & After stop bar \\
\hline & $\mathrm{Y} \quad \mathrm{N}$ & & Before stop bar & After stop bar \\
\hline
\end{tabular}


APPENDIX D: Driver characteristics coding sheet

\begin{tabular}{|c|c|c|c|c|c|c|c|c|c|}
\hline Trial \# & & & & $\begin{array}{l}\text { Dri } \\
\text { Nol }\end{array}$ & $\begin{array}{l}\text { r White/ } \\
\text { hite }\end{array}$ & Driver R & & & \\
\hline & & $F$ & $\mathrm{U}$ & W & NW & Unknwn & Blck & Ltno/Hspnc & Asian Other \\
\hline & $\mathrm{M}$ & $F$ & $\mathrm{U}$ & $\mathrm{W}$ & NW & Unknwn & Blck & Ltno/Hspnc & Asian Other \\
\hline & $\mathrm{M}$ & $\mathrm{F}$ & $\mathrm{U}$ & $\mathrm{W}$ & NW & Unknwn & Blck & Ltno/Hspnc & Asian Other \\
\hline & $\mathrm{M}$ & $F$ & $\mathrm{U}$ & $\mathrm{W}$ & NW & Unknwn & Blck & Ltno/Hspnc & Asian Other \\
\hline & $\mathrm{M}$ & $\mathrm{F}$ & $\mathrm{U}$ & $\mathrm{W}$ & NW & Unknwn & Blck & Ltno/Hspnc & Asian Other \\
\hline & $\mathrm{M}$ & $\mathrm{F}$ & $\mathrm{U}$ & $\mathrm{W}$ & NW & Unknwn & Blck & Ltno/Hspnc & Asian Other \\
\hline & M & $\mathrm{F}$ & $\mathrm{U}$ & $\mathrm{W}$ & NW & Unknwn & Blck & Ltno/Hspnc & Asian Other \\
\hline & $\mathrm{M}$ & $\mathrm{F}$ & $\mathrm{U}$ & $\mathrm{W}$ & NW & Unknwn & Blck & Ltno/Hspnc & Asian Other \\
\hline & $\mathrm{M}$ & $\mathrm{F}$ & $\mathrm{U}$ & $\mathrm{W}$ & NW & Unknwn & Blck & Ltno/Hspnc & Asian Other \\
\hline & $\mathrm{M}$ & $\mathrm{F}$ & $\mathrm{U}$ & $\mathrm{W}$ & NW & Unknwn & Blck & Ltno/Hspnc & Asian Other \\
\hline & $\mathrm{M}$ & $\mathrm{F}$ & $\mathrm{U}$ & W & NW & Unknwn & Blck & Ltno/Hspnc & Asian Other \\
\hline & $\mathrm{M}$ & $\mathrm{F}$ & $\mathrm{U}$ & $\mathrm{W}$ & NW & Unknwn & Blck & Ltno/Hspnc & Asian Other \\
\hline & $\mathrm{M}$ & $\mathrm{F}$ & $\mathrm{U}$ & $\mathrm{W}$ & NW & Unknwn & Blck & Ltno/Hspnc & Asian Other \\
\hline & M & $\mathrm{F}$ & $\mathrm{U}$ & W & NW & Unknwn & Blck & Ltno/Hspnc & Asian Other \\
\hline & $\mathrm{M}$ & $\mathrm{F}$ & $\mathrm{U}$ & $\mathrm{W}$ & NW & Unknwn & Blck & Ltno/Hspnc & Asian Other \\
\hline & $\mathrm{M}$ & $\mathrm{F}$ & $\mathrm{U}$ & $\mathrm{W}$ & NW & Unknwn & Blck & Ltno/Hspnc & Asian Other \\
\hline & $\mathrm{M}$ & $\mathrm{F}$ & $\mathrm{U}$ & W & NW & Unknwn & Blck & Ltno/Hspnc & Asian Other \\
\hline & $\mathrm{M}$ & $\mathrm{F}$ & $\mathrm{U}$ & $\mathrm{W}$ & NW & Unknwn & Blck & Ltno/Hspnc & Asian Other \\
\hline & $\mathrm{M}$ & $\mathrm{F}$ & $\mathrm{U}$ & $\mathrm{W}$ & NW & Unknwn & Blck & Ltno/Hspnc & Asian Other \\
\hline & $\mathrm{M}$ & $\mathrm{F}$ & $\mathrm{U}$ & W & NW & Unknwn & Blck & Ltno/Hspnc & Asian Other \\
\hline & $\mathrm{M}$ & $\mathrm{F}$ & $\mathrm{U}$ & W & NW & Unknwn & Blck & Ltno/Hspnc & Asian Other \\
\hline & $\mathrm{M}$ & $\mathrm{F}$ & $\mathrm{U}$ & W & NW & Unknwn & Blck & Ltno/Hspnc & Asian Other \\
\hline & M & $\mathrm{F}$ & $\mathrm{U}$ & W & NW & Unknwn & Blck & Ltno/Hspnc & Asian Other \\
\hline & $\mathrm{M}$ & $\mathrm{F}$ & $\mathrm{U}$ & W & NW & Unknwn & Blck & Ltno/Hspnc & Asian Other \\
\hline & $\mathrm{M}$ & $\mathrm{F}$ & $\mathrm{U}$ & W & NW & Unknwn & Blck & Ltno/Hspnc & Asian Other \\
\hline & $\mathrm{M}$ & $\mathrm{F}$ & $\mathrm{U}$ & $\mathrm{W}$ & NW & Unknwn & Blck & Ltno/Hspnc & Asian Other \\
\hline & $\mathrm{M}$ & $\mathrm{F}$ & $\mathrm{U}$ & W & NW & Unknwn & Blck & Ltno/Hspnc & Asian Other \\
\hline & M & $\mathrm{F}$ & $\mathrm{U}$ & W & NW & Unknwn & Blck & Ltno/Hspnc & Asian Other \\
\hline & $\mathrm{M}$ & $\mathrm{F}$ & $\mathrm{U}$ & W & NW & Unknwn & Blck & Ltno/Hspnc & Asian Other \\
\hline & & $\mathrm{F}$ & $\mathrm{U}$ & $\mathrm{W}$ & NW & Unknwn & Blck & Ltno/Hspnc & Asian Other \\
\hline & $\mathrm{M}$ & $\mathrm{F}$ & $\mathrm{U}$ & W & NW & Unknwn & Blck & Ltno/Hspnc & Asian Other \\
\hline & $\mathrm{M}$ & $\mathrm{F}$ & $\mathrm{U}$ & $\mathrm{W}$ & NW & Unknwn & Blck & Ltno/Hspnc & Asian Other \\
\hline & $\mathrm{M}$ & $\mathrm{F}$ & $\mathrm{U}$ & W & NW & Unknwn & Blck & Ltno/Hspnc & Asian Other \\
\hline & $\mathrm{M}$ & $\mathrm{F}$ & $\mathrm{U}$ & $\mathrm{W}$ & NW & Unknwn & Blck & Ltno/Hspnc & Asian Other \\
\hline & $\mathrm{M}$ & $\mathrm{F}$ & $\mathrm{U}$ & W & NW & Unknwn & Blck & Ltno/Hspnc & Asian Other \\
\hline & $\mathrm{M}$ & $\mathrm{F}$ & $\mathrm{U}$ & W & NW & Unknwn & Blck & Ltno/Hspnc & Asian Other \\
\hline & $\mathrm{M}$ & $\mathrm{F}$ & $\mathrm{U}$ & W & NW & Unknwn & Blck & Ltno/Hspnc & Asian Other \\
\hline & $\mathrm{M}$ & $\mathrm{F}$ & $\mathrm{U}$ & W & NW & Unknwn & Blck & Ltno/Hspnc & Asian Other \\
\hline
\end{tabular}




\section{APPENDIX E: Screening Form for Focus Group}

1) Name:

2) Email:

3) Age:

4) Ethnicity / Race:

5) Gender:

7) Number of years you have lived in Portland:

8) What part of the city (N, NE, NW, SE, SW) do you live in?

9) How much time do you spend walking per week on average?

10) Where/why do you usually walk? (example: to work, to the grocery store) 


\section{APPENDIX F: Interview Guide for Focus Groups}

Introduction: Good evening and welcome to our session. Thanks for taking the time to join us tonight. My name is [X] and assisting me is [X]. We're working with researchers at Portland State University, along with Oregon Walks, who asked us to speak with people of color about their experiences while walking in Portland. They want to know about positive and negative experiences you have had, and what barriers you face when getting around Portland on foot. We are having discussions like this with several groups in Portland.

There are no wrong answers but rather differing points of view. Please feel free to share your point of view even if it differs from what others have said. Keep in mind that we're just as interested in negative comments as positive comments, and at times the negative comments are the most helpful. While we can't control what people say when they leave this room, we ask everyone to respect the confidentiality of this room and not to share any personal details about people who have participated tonight. We also ask that you do not share any stories that we would be required to report to authorities. We ask that your turn off your phones or pagers. If you cannot and if you must respond to a call, please step outside while you are on the phone, and rejoin us as quickly as you can.

[Motion to the tape-recorder.] We're tape-recording the session because we don't want to miss any of your comments. People often say very helpful things in these discussions and we can't write fast enough to get them all down. We will be on a first-name basis tonight, and we won't use any names in our reports. You may be assured of complete confidentiality. The reports will go back to the researchers to help them understand how people feel about walking in Portland.

Let's begin. We've placed name cards on the table in front of you to help us remember each other's names. Let's find out some more about each other by going around the table. Tell us your name and where you live.

1. Opening question [5 minutes]:

a. Where in town do you usually walk? Where do you walk to? Who do you walk with?

2. I am interested in hearing about what experiences you have had while walking in your neighborhood, or other places in Portland. First, I would like to hear about positive experiences, then I'll ask you to share any negative experiences. [15 minutes]

a. What are some positive experiences you have had while walking in Portland?

b. Have you had any negative experiences while walking in Portland?

3. Now, let's talk specifically about your interactions interacting with car drivers while you are walking. Have you ever had any negative experiences with drivers while walking? [20 minutes]

a. Probes if not mentioned or little discussion: 
i. Experience crossing the street

ii. What effect does this have on you?

4. What role do you think your race plays in these experiences as a pedestrian interacting with drivers? Or some other characteristics like age, gender, etc.? [20 minutes]

a. Probes if not mentioned or little discussion:

i. Do you feel this way in specific neighborhoods? How does this feeling compare to different neighborhoods? How does Portland compare to other cities? Why do you think this is so?

ii. Have you ever felt like drivers treat you differently when you are walking because you are a person of color?

iii. What is your experience crossing the street, specifically?

iv. What effect does this have on you?

5. Researchers recently looked at crosswalks, and black pedestrians had to wait longer and were passed by more drivers before someone would stop so they could cross the street compared to White pedestrians. Drivers who did stop were also more likely to infringe into the Black pedestrians' space. [10 minutes]

a. How do you feel about this? Does this match your experience?

b. Do you have any ideas about what might be done to change people's behavior?

Thank you so much for participating today. We have provided a large index card for each of you. If there is anything else you would like to share that you did not get a chance to share during this meeting, please feel free to fill out that and leave it for me. We are happy to hear about anything you think is important regarding your experiences walking in Portland. [5 minutes] 
Transportation Research and Education Center

Portland State University

1900 S.W. Fourth Ave., Suite 175

Portland, OR 97201 